Journal of Business \& Management (COES\&RJ-JBM)

ISSN (E): 2306-7179 ISSN (P): 2306-8043

Publisher: Centre of Excellence for Scientific \& Research Journalism, COES\&RJ LLC

Online Publication Date \& Issue: 1st October 2016, Vol.4, No.4, October 2016

http://centreofexcellence.net/J/JBM/JBM\%20Mainpage.htm

\title{
The impact of Business Ethics on the management of human resources in the business organization.
}

\begin{abstract}
Dr. Keltouma Boufatah
Abstract:

Embodied ethics behaviors take into account the non-violation of norms, standards and beliefs in society on the part as well as the laws and moral codes in force by another, and an organization can work to embody social responsibility through ethical behaviors toward human resources through various means cover the entire multiple and diverse subactivities of the Department of Human Resources, social responsibility in business organizations is the moral commitment and responsible action at a number of parties and are stakeholders, and of the most important parties benefiting from programs of social responsibility, we find both the community and the environment, including social responsibility toward workers and include respect for labor laws, and ensure the worker's right to training and continuous training, and trade union rights, and involving them in decision-making, achieve job security and the security of work-related accidents, etc.
\end{abstract}

And it covers human resources management ethics of these emerging ethical issues about the relationship between employers and employees, such as the rights and duties owed between these not be done in isolation from SOCIAL responsibility

Then, the question is: What is the impact of business ethics and social responsibility to the human resources department? In order to delve into this subject, we decided to address the following.

I- Theoretical framework: the management of human resources, and business ethics and social responsibility

II. Applied framework of the research;

Status: Aramco

Status: Sonatrach, the Algerian

Status: Sonelgaz company

Keywords:

business ethics, corporate social responsibility, human resources management, workers’ activities

\section{Citation:}

Boufatah, Dr. Keltouma (2016); The impact of Business Ethics on the management of human resources in the business organization. (COES\&RJ-JBM) Vol.4, No.4, pp.182-203

This work is licensed under a Creative Commons Attribution 4.0 International License. 


\section{تأثير أخلاقيات الأعمال على تسيير الموارد البشرية في منظمة الأعمال.

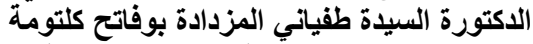

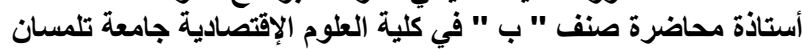

تتجسد الأخلاق بسلوكيات نراعي عدم خرق القواعد و والمعايير والمعتقدات في المجتمع من جانب وكذلك القوانين

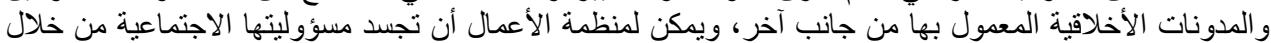

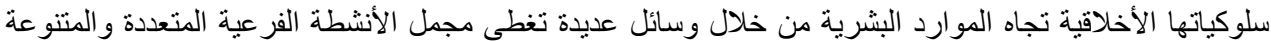

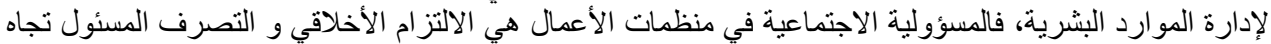

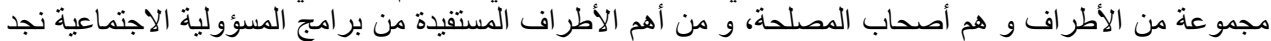

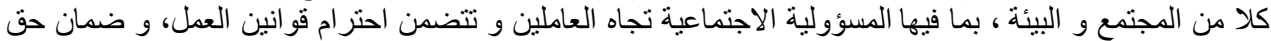

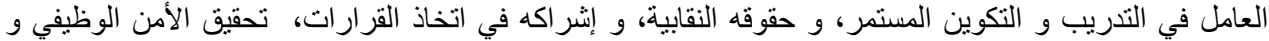

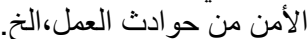

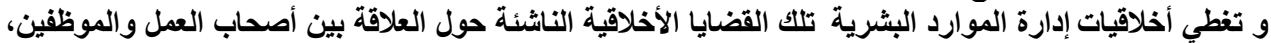
مثل الحقوق والواجبات المستحقة بين هؤلاء ولا يتم ذلك بمعزل عن المسؤولية الاجتماعيةإلن فالسؤال العال المطروح

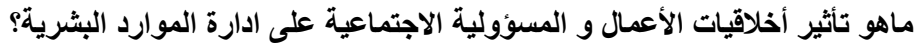

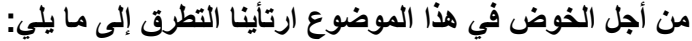

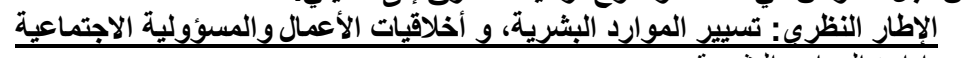

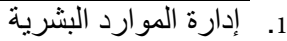

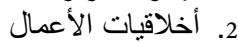

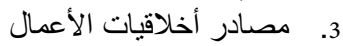

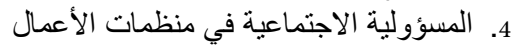

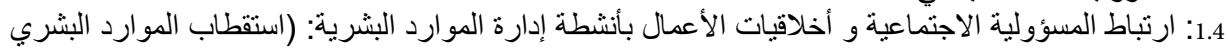

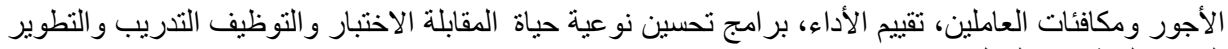

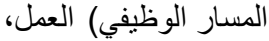

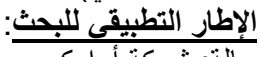

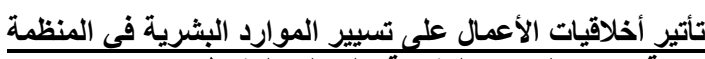
حالة: شركة أرامكو حالة: شركة سونة شناطر الك الجز ائرية

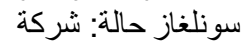
الكلمات مفتاح: أخلاقيات الأعمال، المسؤولية الاجتماعية، إدارة الموارد البشرية، العمال، النشاطات.

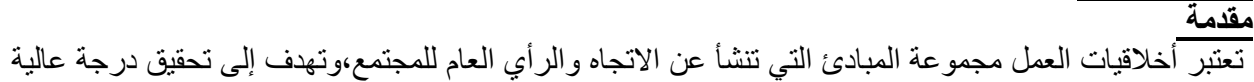

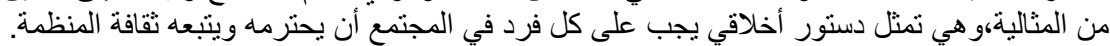

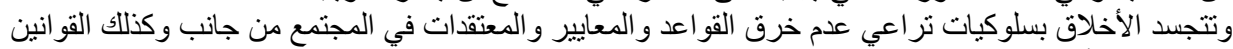

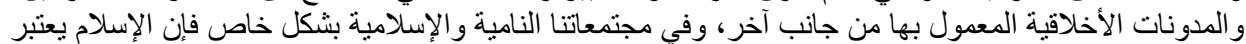

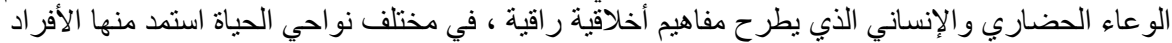

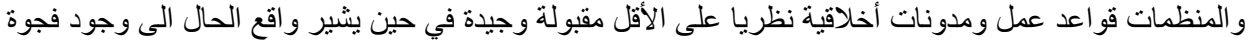

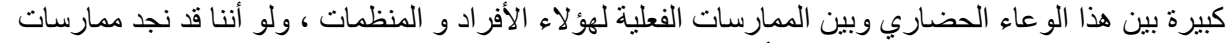

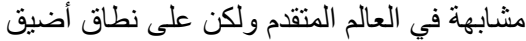

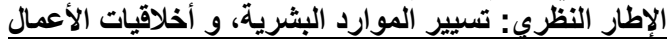
أولا: إدارة الموارد البشرية: حضت البرارد إدارة الموارد البشية البشرية بتعاريف مختلفة نذكر أهمها فيما يلي فرنش:هي عملية اختيار واستخدام وتتمية وتعويض المئية الموارد البشرية بالمنظمة.

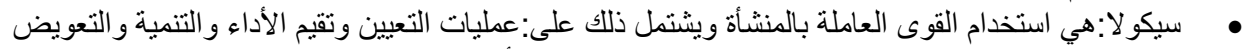

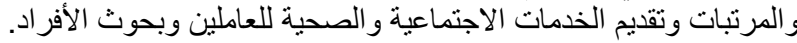

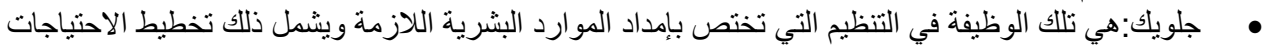
من القوى العاملة والبحث عنها وتثغيلها و الاستغناء عنها 
• شرودن وشيرمان بي :إدارة الموارد البشرية تشتمل على عمليات أساسية يجب أداؤها وقو اعد يجب إنباعها،

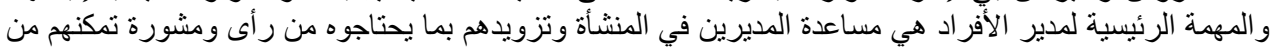

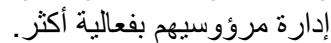

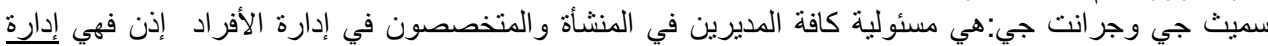

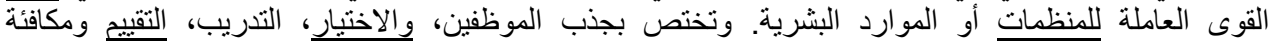

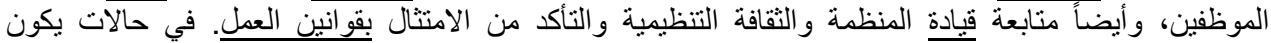

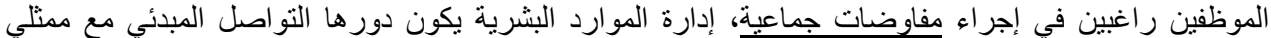
الموظفين (في العادة أتحادات العمال).

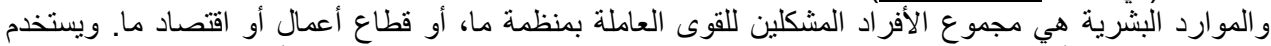

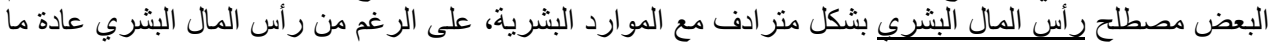

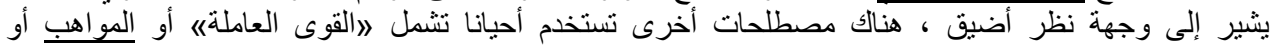

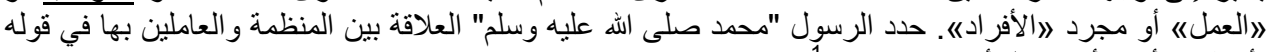

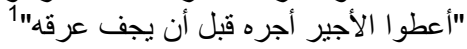

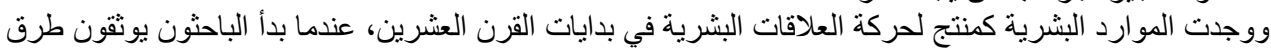

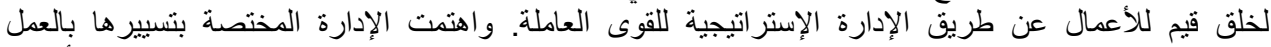

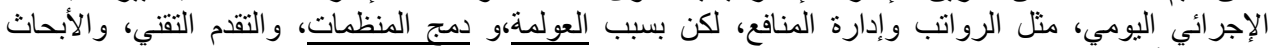

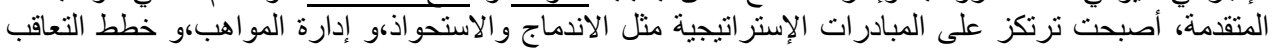

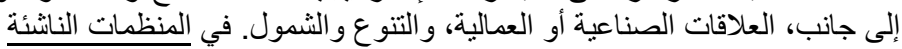

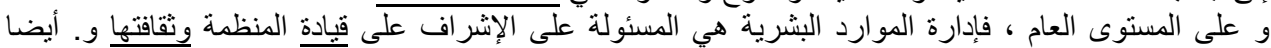

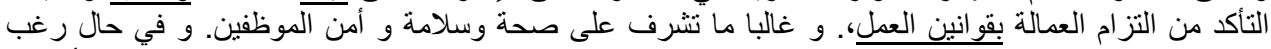

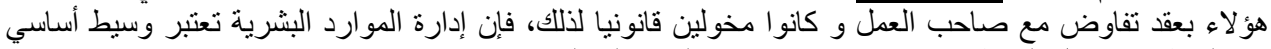

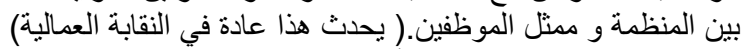

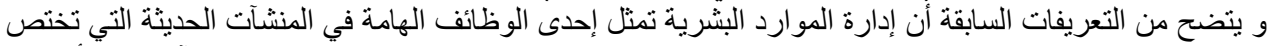

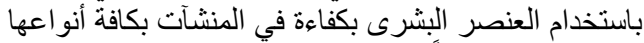

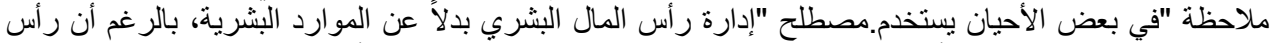

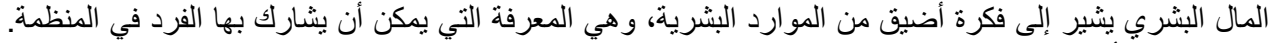

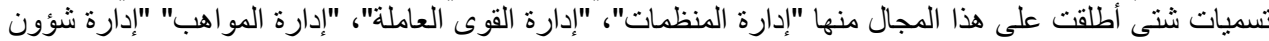

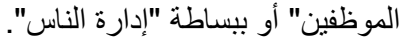

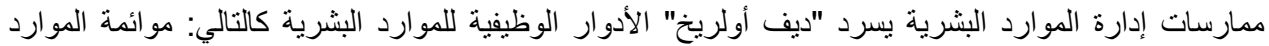

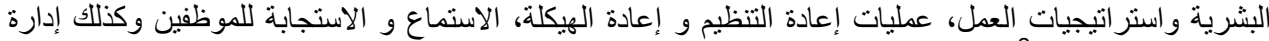

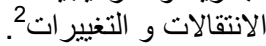

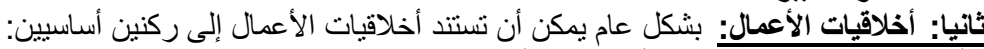

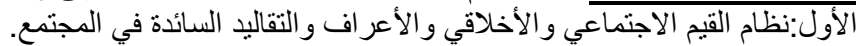

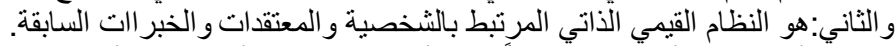

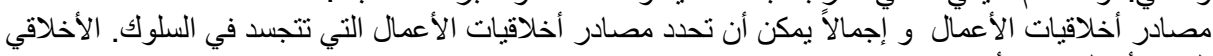
الحميد أو السيئ بالأتي ألاعي ثقافة المجتمع وقيمه و عاداتئ.

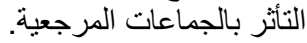

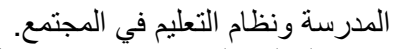
إعلام الدولة و الصحافة ومؤسسات الرئي أي.

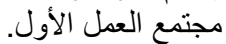

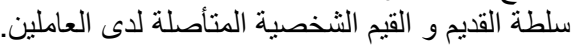

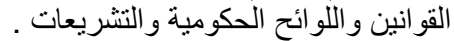

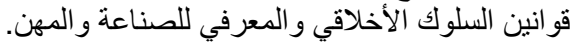

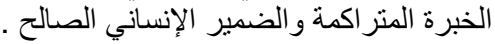

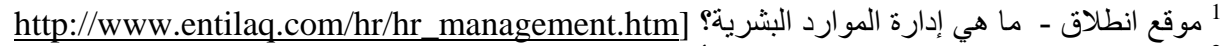
2 النمر، سعود محمد و آخرون. الإدارة العامة الأسس و الوظائف. الرئرة الرياض: مطابع الفرزدق، 1994. 


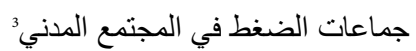

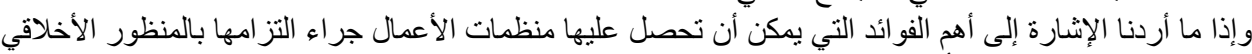

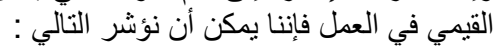

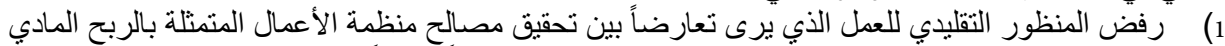

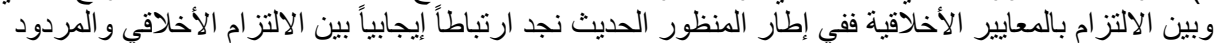

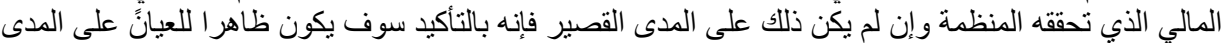

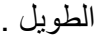

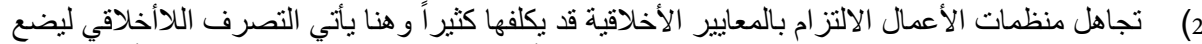

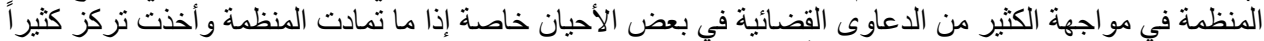

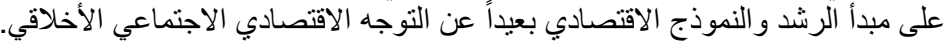

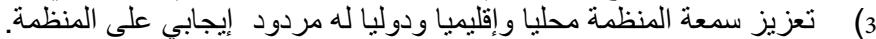

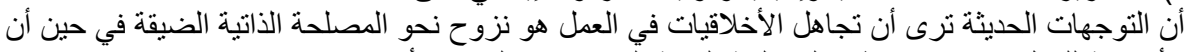

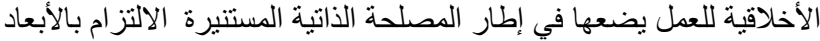

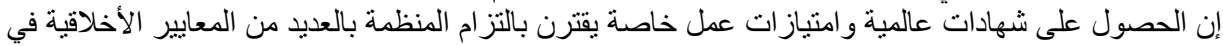

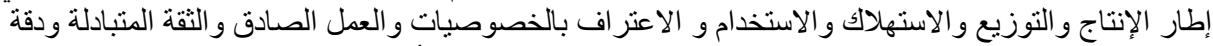

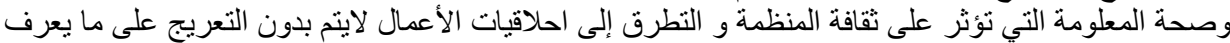

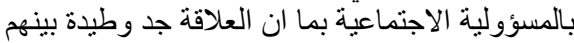

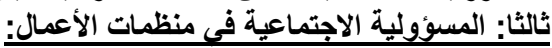

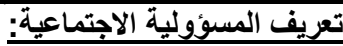

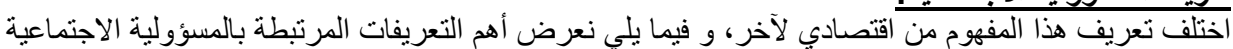

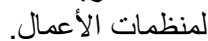
التعريف الأول: يرى كارول (Carrol) أن المسؤولية الاجتماعية الكلية للمنظمة تشمل على مستويات أربعة هي: كفاءة

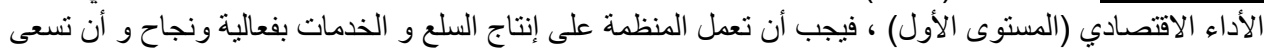

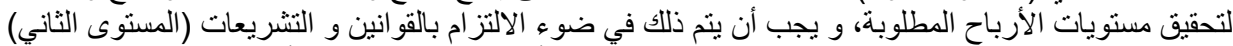
التي تعمل المنظمة في ظلها، هذا و ينتظر المجتمع من المنظمة أن تهتم بالمسؤوليات الأخلاقية (المستوى الثالثالث)

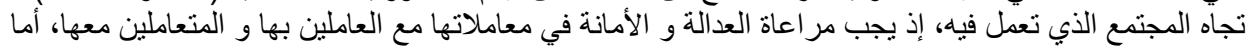

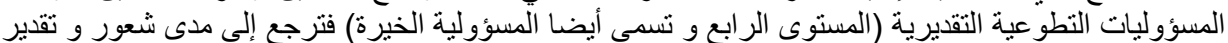

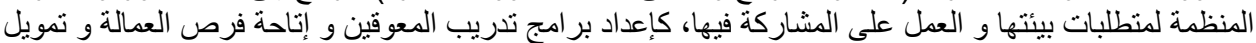

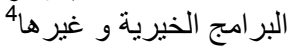
التعريف الثناني: التيرئ

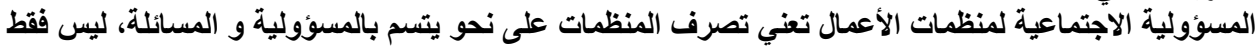

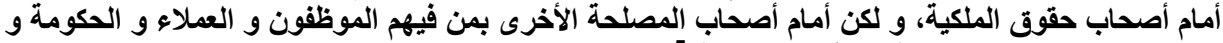

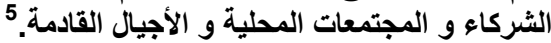

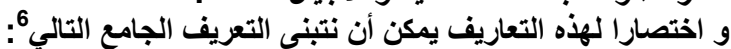

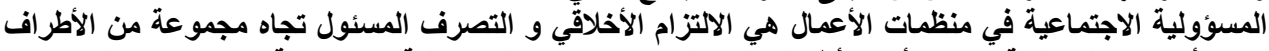

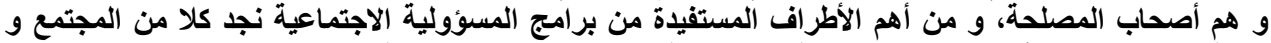

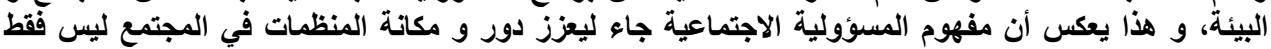

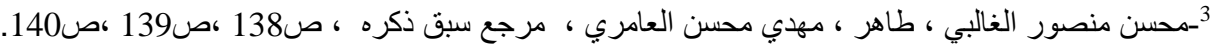

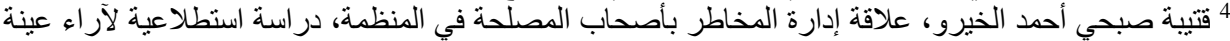

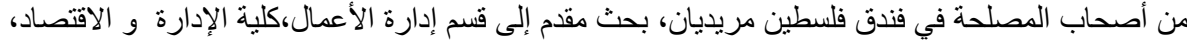

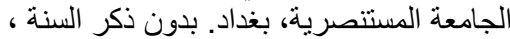

حسين الاسرج،المسؤولية الاجتماعية للشركات،مجلة جسر التنمية، سلسلة دوريـة تعنى بقضـايا التنميـة في الدول 5

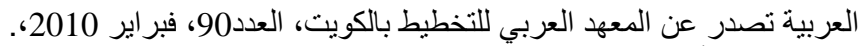

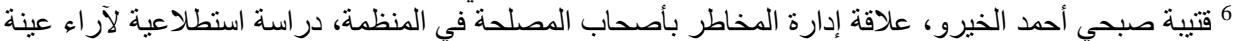

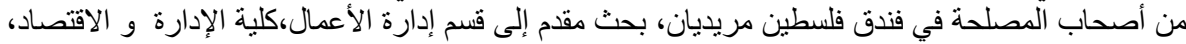

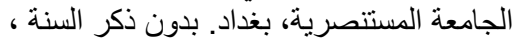


ككيان اقتصادي إنما أيضا ككيان اجتماعي يسهم في حل مشكلات المجتمع و الحفاظ على البيئة التي يعمل في إطارها. نشأة مفهوم المسؤولية الاجتماعية لمنظمات الأعمال:

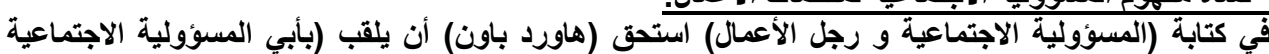
لقطاع الأعمال)، حيث أسس أول تعريف لهذا المفهوم بأنه :"التزام منظمات الأعمال بأداء أنثطتها بحيث تتوافت التقاع

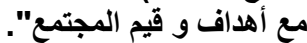

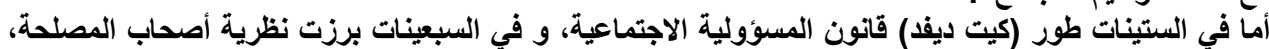

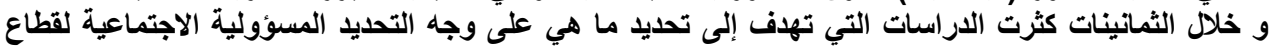

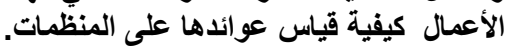

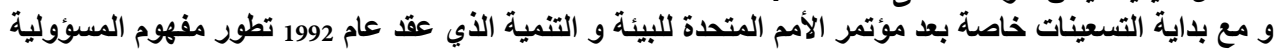

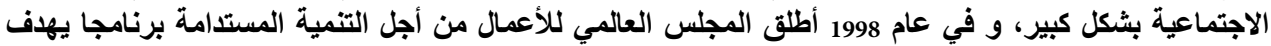

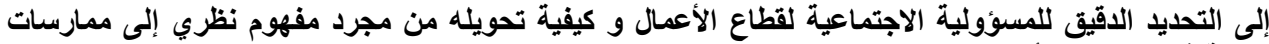

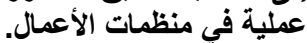

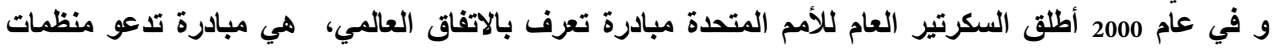

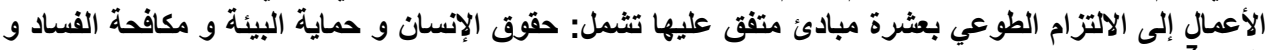
غير هال. أهمية المسؤولية الاجتماعية في منظماتية الإئية الأعمال: تتمثل المكاسب التي تجنيها منظمات الأعمال من برامج تعمل المسؤولية الاجئماعية على تحسين و تطوير الإئية صورة المنظمة أمام المجتمع.

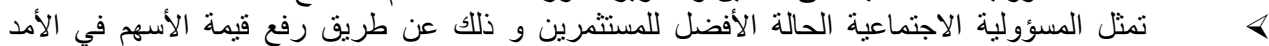

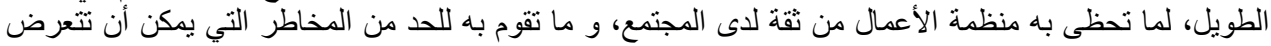

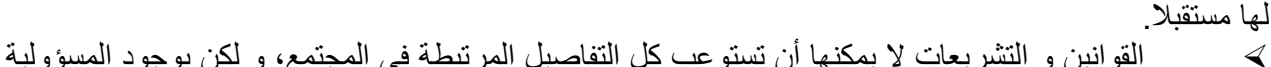

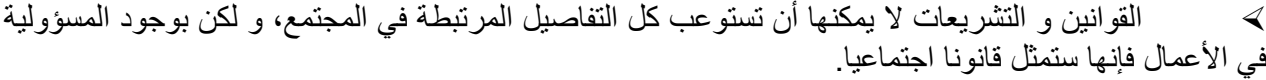

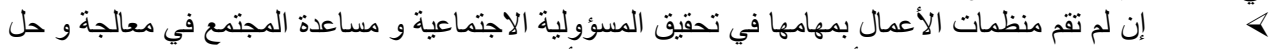

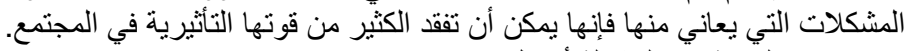

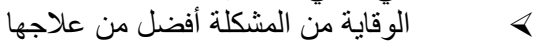

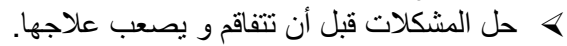

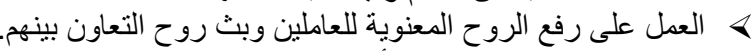

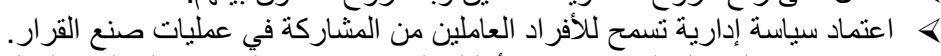

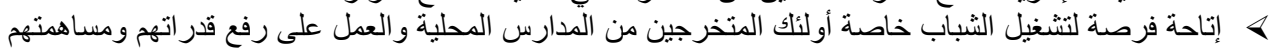

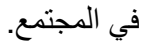

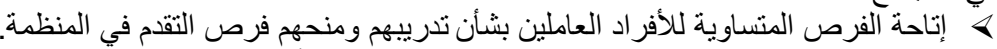

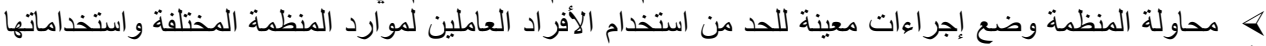

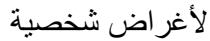
\& اعتماد برنامج أو نموذج للسلوك الأخلافي لمعالجة ممارسات العاملين ذات العلاقة بالاعتبارات الثخصية

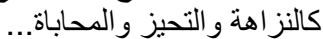
ه التزام المنظمة بتطبيق القو انين والتعليمات الخاصة بالعمل وتنفيذها بعدالة على الأفراد العاملين و إقناعهم بذلك

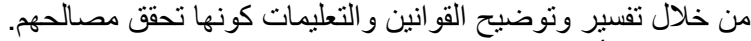

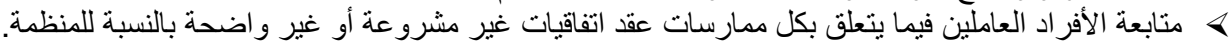

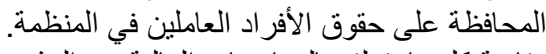

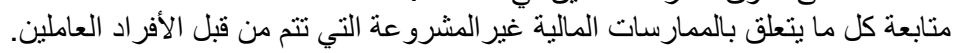

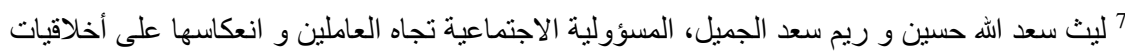

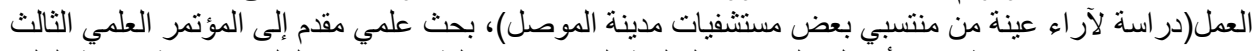

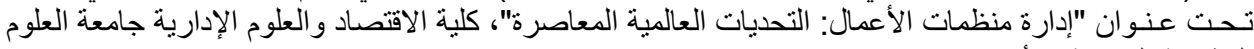
التطبيقية الخاصة، الأردن، 27 - 29 نيسان 2009، الأنان 
مراحل تطور اهتمام الثركات بالمسؤولية الاجتماعية تطور اهتمام منظمات الأعمال بالمسؤولية الاجتماعية من خلال المر احل الثلاثة التالية:":

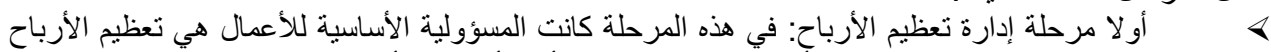

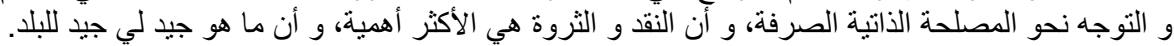

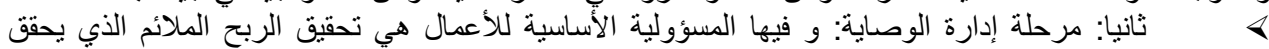

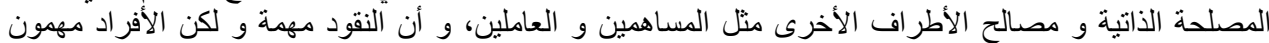
أيضا، و أن ما هو جيد للشركات جيد اللاطرات اللبلا.

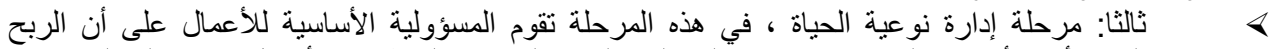

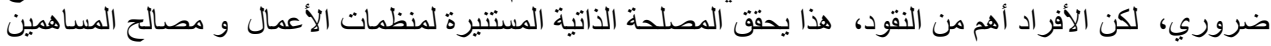

ارتباط المسؤولية الاجنماعية بنظرية أصحاب المصلحة:

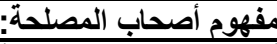

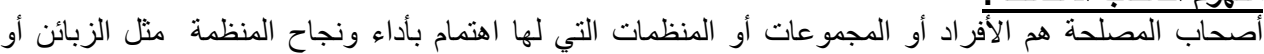

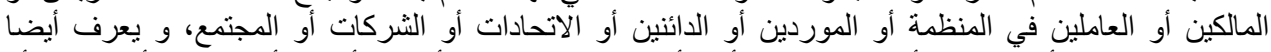

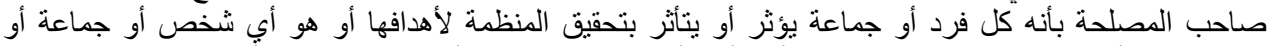

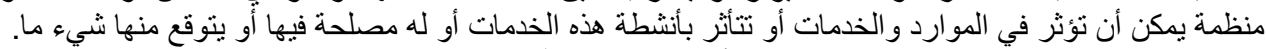

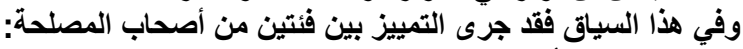

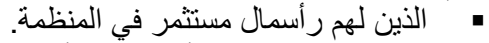

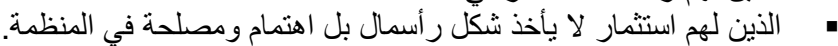

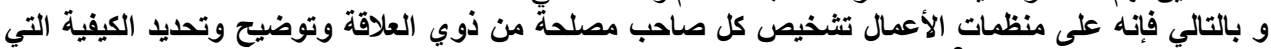

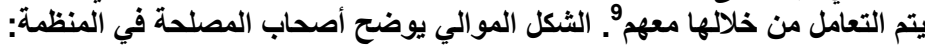
الثكل(1): أصحاب المصالح أو المستفيدون من وجود الثود منظمات الأعمال

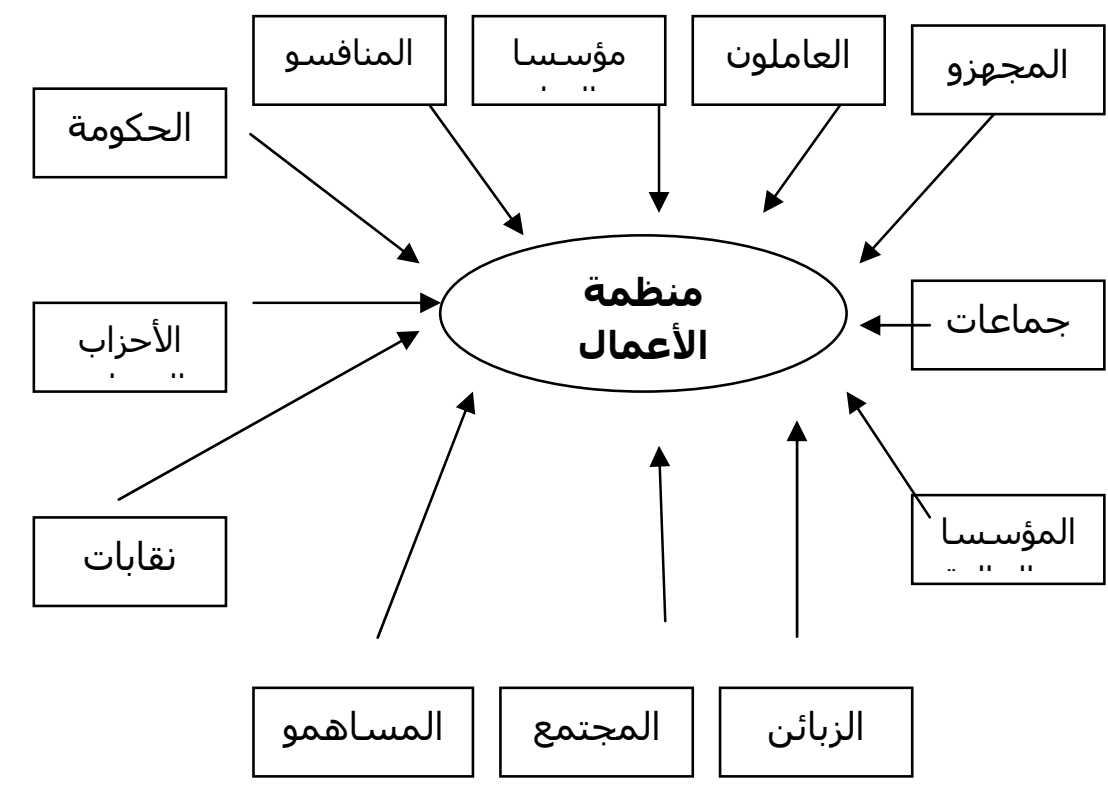

8 نجم عبود نجم، أخلاقيات علم الإدارة في عالم متغير، منشورات المنظمة العربية للتنمية الإدارية (بحوث و

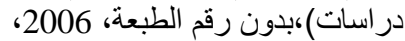

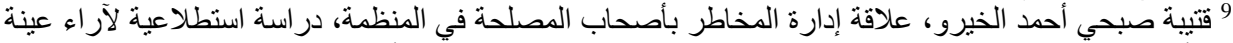

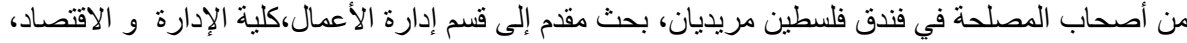
الجامعة المستتصرية، بغداد. بدون ذكر السنة ، فل فئن 
ش (1) : لمصدر: طاهر محسن منصور الغالبي و صالح مهذي محسن العامري ، الإدارة و الأعمال، دار وائل

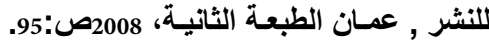

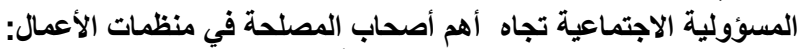

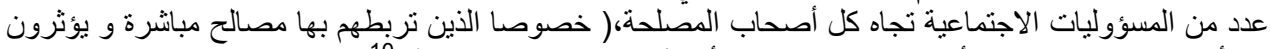

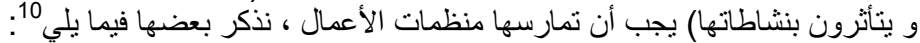

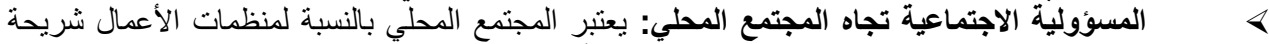

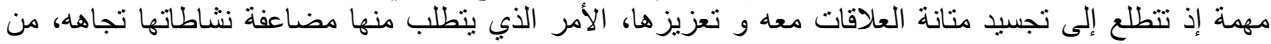

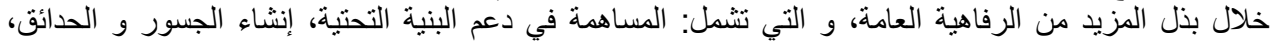

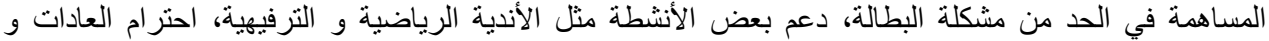

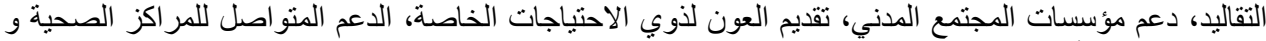

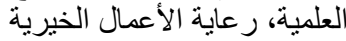
> المية المعؤولية الاجتماعية تجاه الزبائن: تتمثل في تقديم المنتجات بأسعار و نوعيات مناسبة، الإعلان

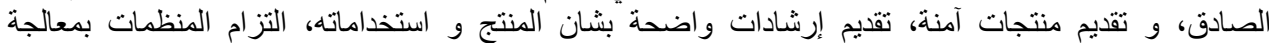
الأضرار التي تحدث بعد البيع، و الالتزام بالنطوير المستمر للمنتجات، و الالتزام بعدم خرق قاعد العمل مثل لتل

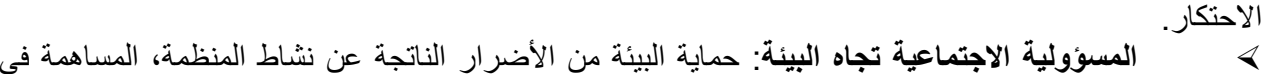

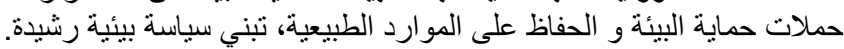

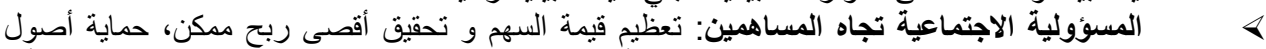

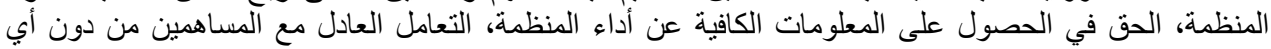

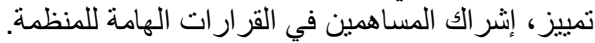

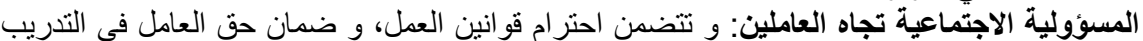

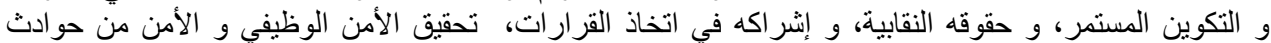
العمل،الخ.

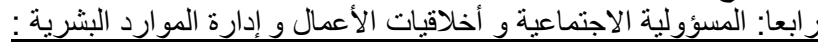

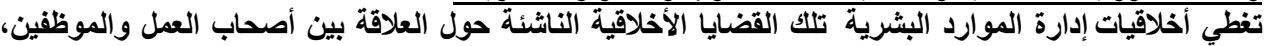

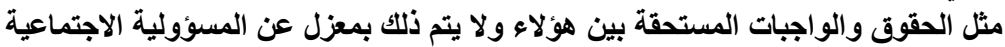

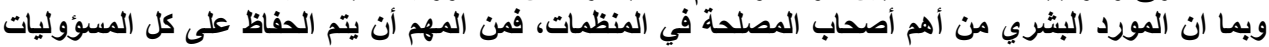

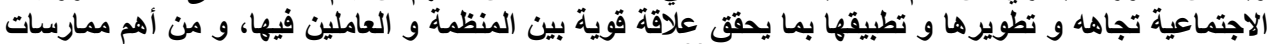

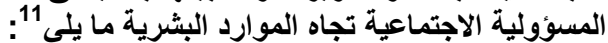

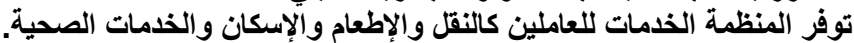

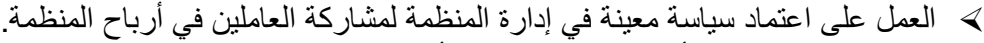

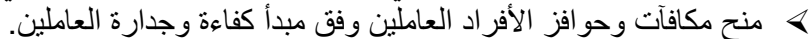

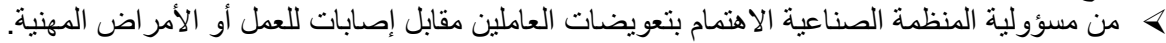

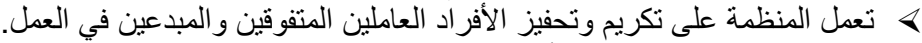
> إعداد وتنفيذ برامج توعية للأفراد العاملين تتضمن المعايير المهمة المعتمدة على المستوى الاجتماعي والبيئي

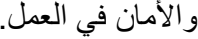
\& اعتماد بر امج أو سياسة معينة لإيجاد فرص لانجاز أعمال صغيرة للأفر اد العاملين.

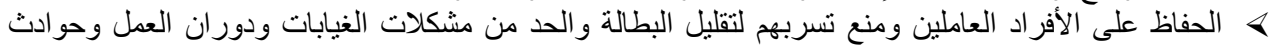

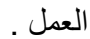

10 طاهر محسن منصور الغالبي و صالح مهدي محسن العامري ، الإدارة و الأعمال، دار وائل للنشر , عمـان

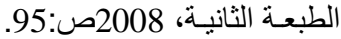

11 قتيبة صبحي أحمد الخيرو، علاقة إدارة المخاطر بأصحاب المصلحة في المنظمة، دراسة استطلاعية لآراء عينة

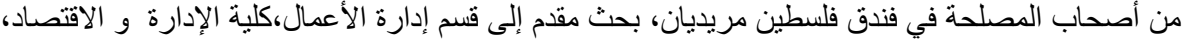
الجامعة المستتصرية، بغداد. بدون ذكر السنة ، فئل 
إعداد سياسة تمنع الأفراد العاملين من تسريبهم للمعلومات المهمة أو السرية الخاصة بأعمال المنظمة خاصة الأفراد المباد

تحتل الموارد البشرية في منظمات الأعمال الحيثة مكانة رفيعة وتلعب دورا فعالا في عصر أصبح التغيير فيه أمبرا

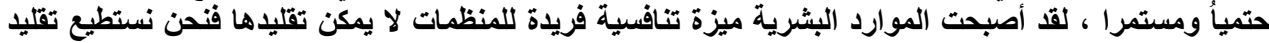

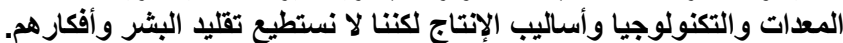

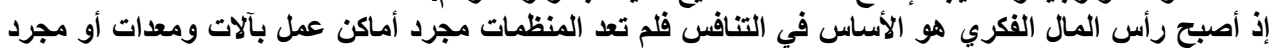

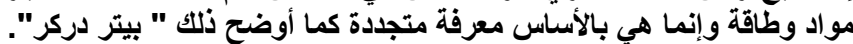

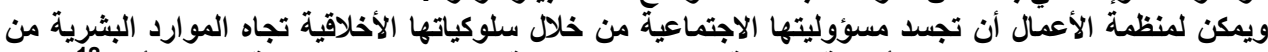

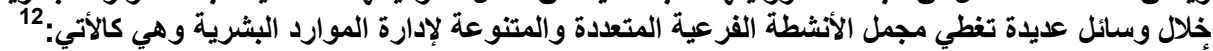

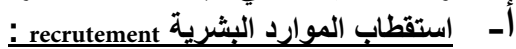

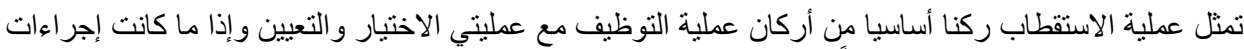

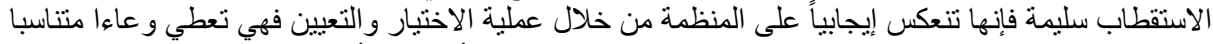

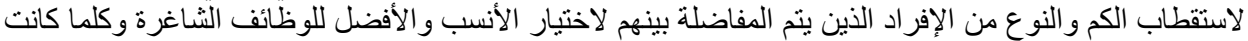

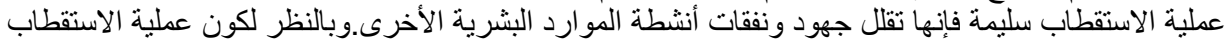

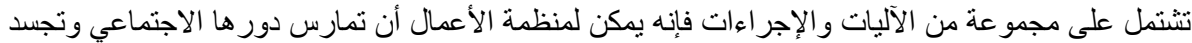

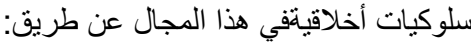

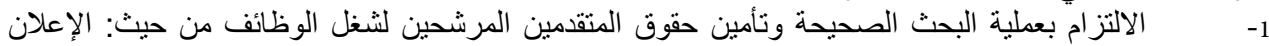

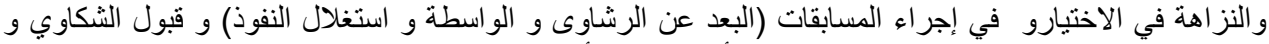

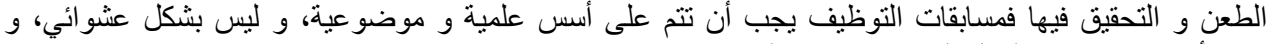

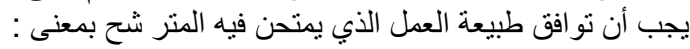

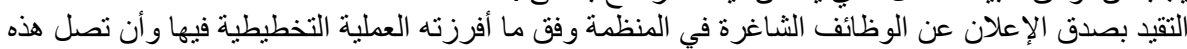

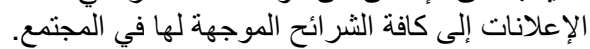

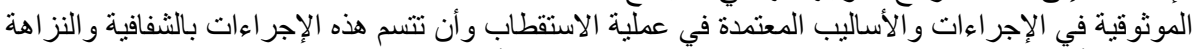

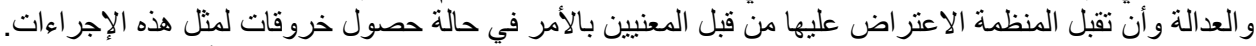

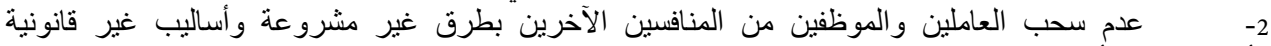

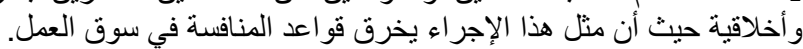

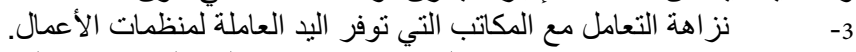

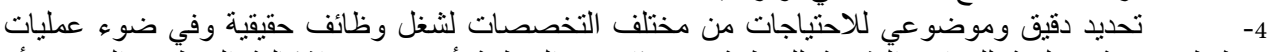

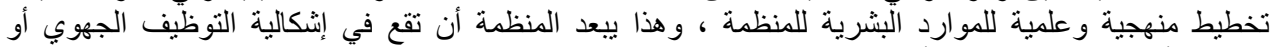

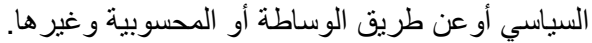

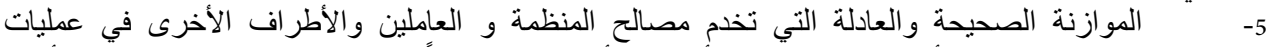

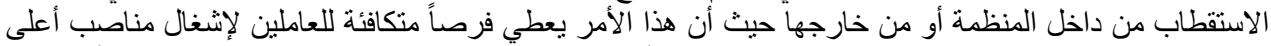

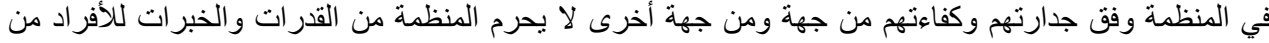

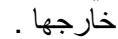
أي الموازنة بين الاستقطاب الداخلي و الخارجي، حيث يفيد الأول في منح فرص ترقية الإنية عمال المنظمة. 6-

7-

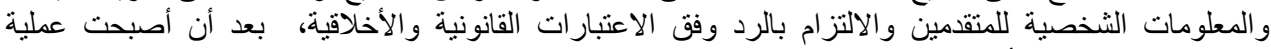
الاستقطاب تجري وفق أساليب الاتصال الالكتروني.

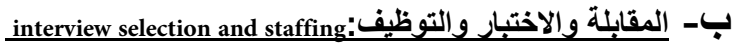

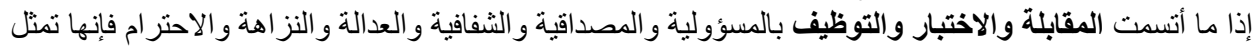

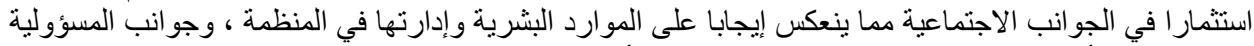

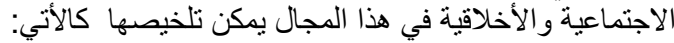

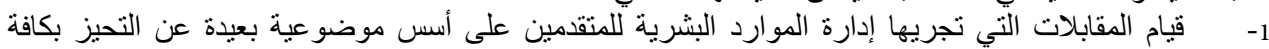
أشكاله و أن تكون الأساليب و الطرق و الإجر اءات في هذه الأخيرة واضحة البحة وشفافة و وعادلة.

$$
\text { 12 محسن منصور الغالبي ، طاهر ، مهدي محسن ، المرجع السابق ،260. }
$$


2- إتاحة فرص متساوية لجميع المرشحين بعرض كفاءاتهم ومهار اتهم بغية أن تكون عملية الاختبار و التعيين

$$
\text { سليمة. }
$$

3-

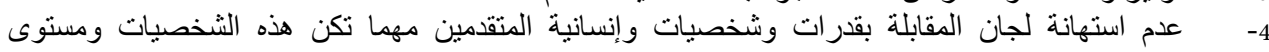

مهار اتهم.

-5 - 5 -

6-

الخطأ

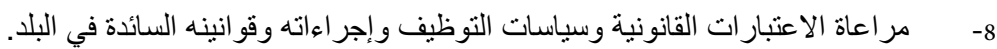

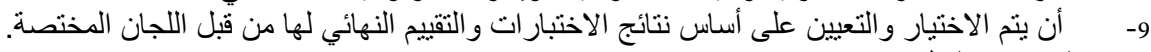

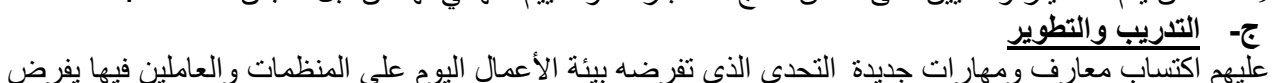

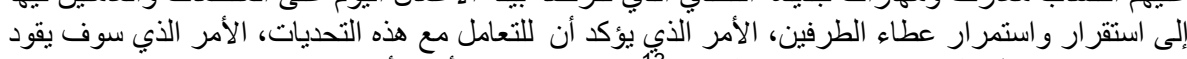

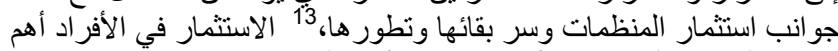

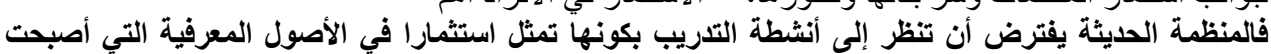

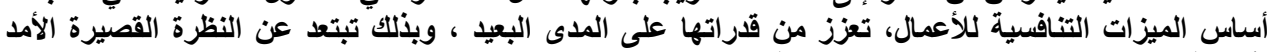

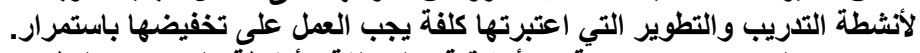

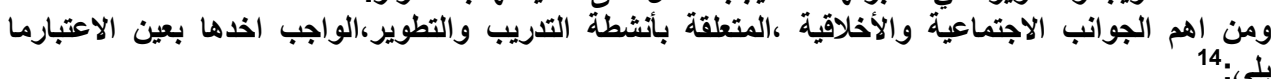
1- الي الحفاظ على الحقوق المهمة للعاملين في المنظمة وبذلك لا يمكن استبعاد البعض منها لأي سبب كان كالجنس و العرق و اللون و الدين و القو مية و غير ها.

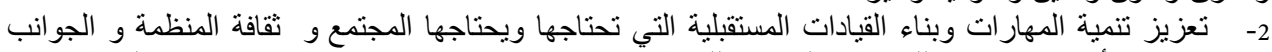

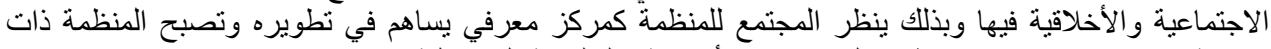

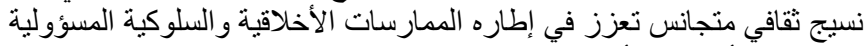

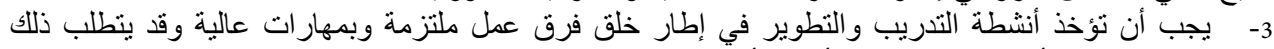
تدريبهم خارج البلاد أو لاى المنظمات الأخرى أو في داخل في التئ المنظمة.

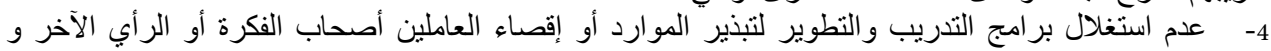

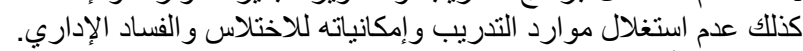

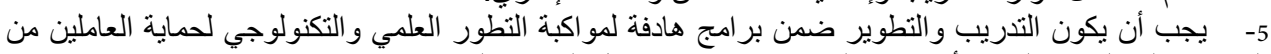

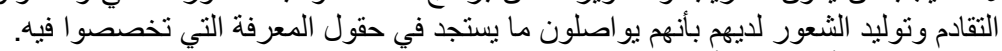

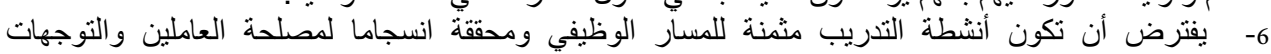
التطويرية في المنظمة.

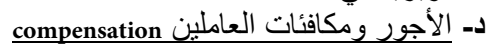

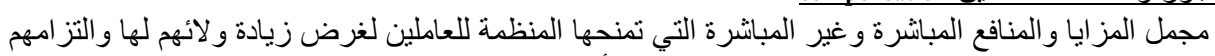

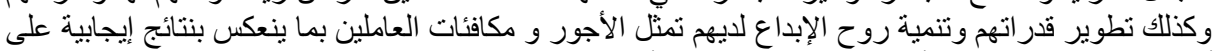

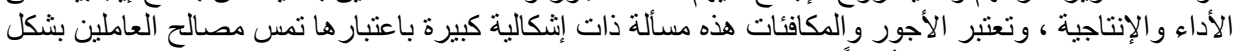

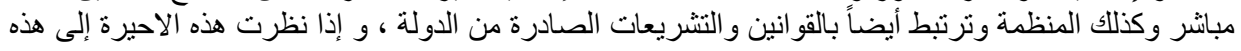

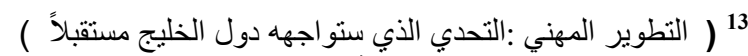

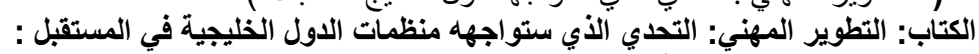

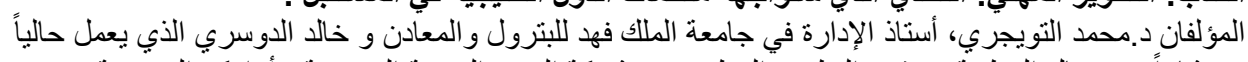

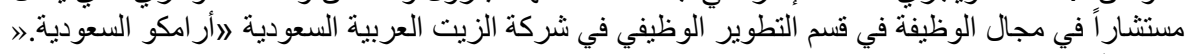

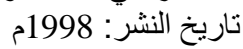

الناشر: مطابع الإيمان للنشر عرض وتثقيم:الرياض - عبدالرحمن أحمد هيجان(مدير عام الاستشارات معهد الإدارة العام) 14 العقدة, أحمد عبد المجيد. تقويم الأداء: نظرة تحليلية على أهداف وأساليب ووسائل تقويم الأداء في الجهاز الحكومي بسلطنة عمان دراسة ميدانية .الإداري. السنة 20 العدد 72 مارس العبد 1998. 
التعويضات بمنظور شمولي وبكونها مرتبطة برفاهية المجتمع وتطوير الأداء في المنظمة تتجسد في الأجور

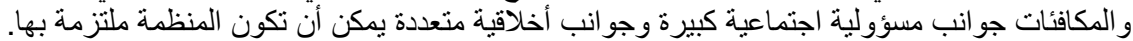

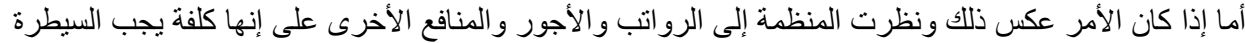

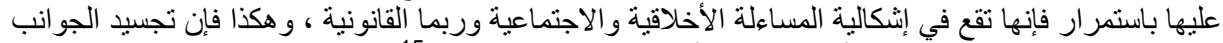

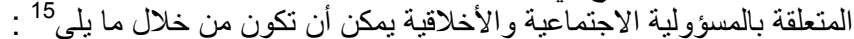

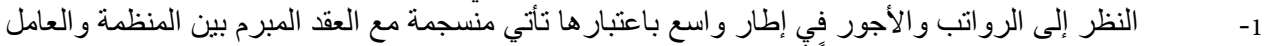

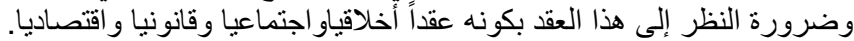

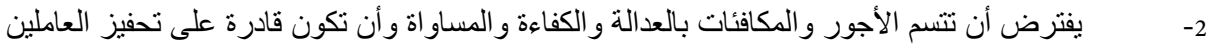

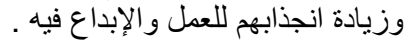

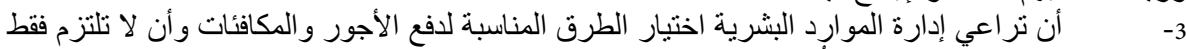
بالطرق التي تحقق مصالحها بعيداً عن مصالح جمئ الفيع الفئات.

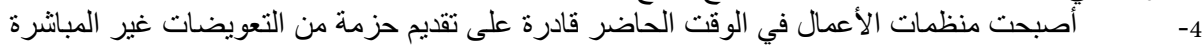

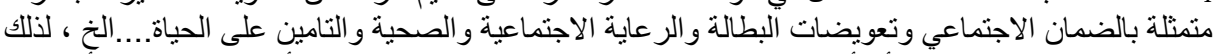

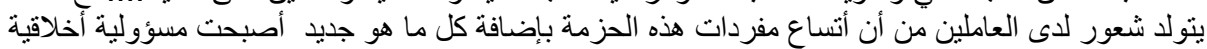

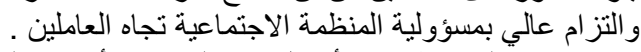

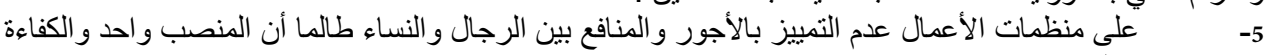
متوفرة بنفس القدر

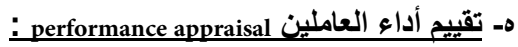

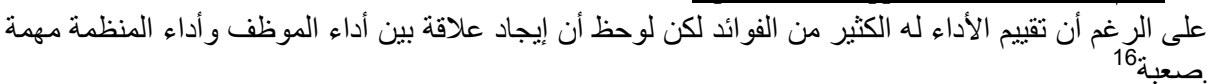

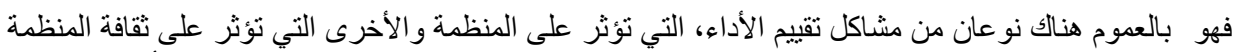

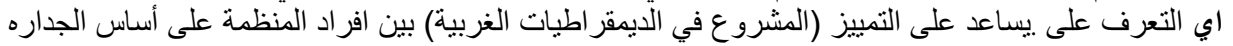

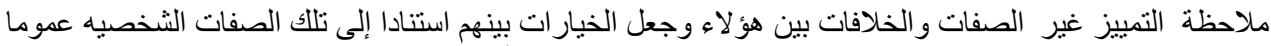

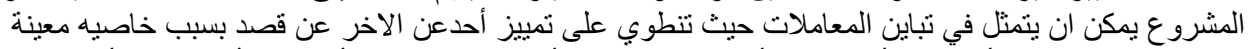

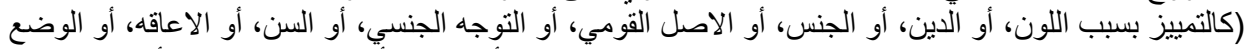

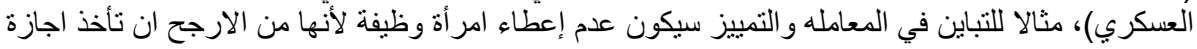

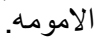

تقييم الأداء هو عملية منهجية دورية لتقييم الأداء الوظيفي والإنتاجية لموظف ما بالرجوع لمعايير موضو عة سلفاً

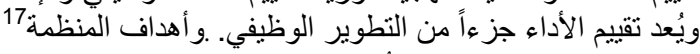

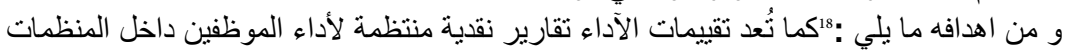

15 نجم عبود نجم، أخلاقيات علم الإدارة في عالم متغير، منشورات المنظمة العربية للتنمية الإدارية (بحوث و

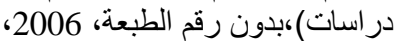
16 الرفاعي, يعقوب السيد يوسف. أثر التدريب أثناء الخدمة على أداء وسلوك الموظفين الدستفيدين من التدريب بدولة

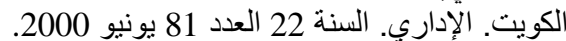

17 الركابي، زين العابدين. يوم العمال العالمي ومستقبل العالم من خلال أزمات البطالة. صحيفة الثرق الأوسط. 6 مايو 2006

18 الصباب, أحمد عبد الله وآخرون. أساسيات الإدارة الحديثة. 2002.(لم أجد بيانات النشر كاملة)خالد الزهراني - 
• التحقق من صحة تقنيات الاختيار وسياسات الموارد البشرية لتلبية منطلبات العمل ومن الطرق الثهيرة لتقييم

استخدام نظام التصنيف العددى، والأي بقوم المديرين، من خلاله، بتسجيل هدف ضد الته عدد من الأهداف أو الرموز.

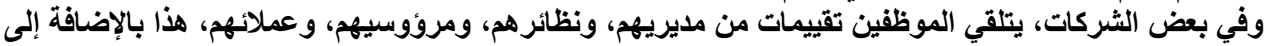

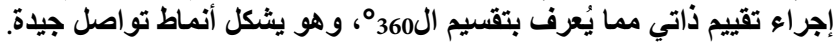

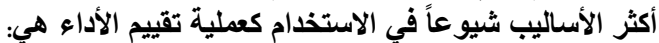
•

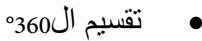
• • • • مقياس المراقية السلوكية

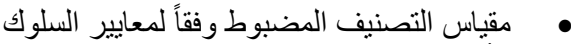
كما أن نُظم السمة القائمة، التي تعتمد على عوامل مثل النزاهة والإخلاص، يشيع استخدامها من قبل الثركات الثركات.

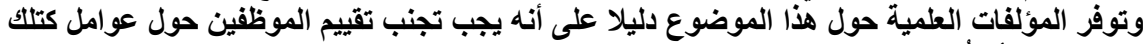

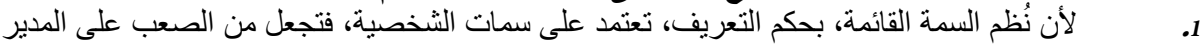

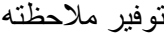

إن تقييم أداء العاملين كأفر اد و كمجاميع وكإدار ات أو عامليز عاملين فنبين هو من صميم عمل إدارة الموارد البشرية

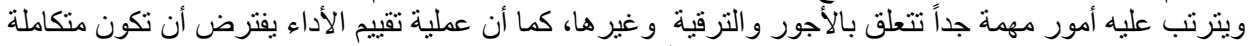

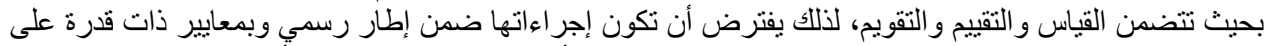

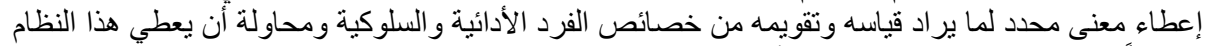

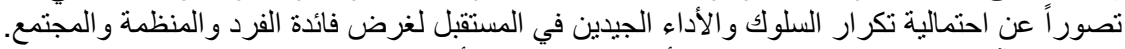

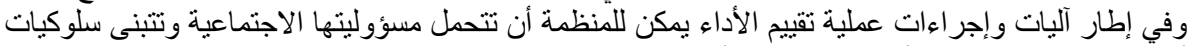

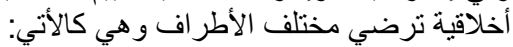

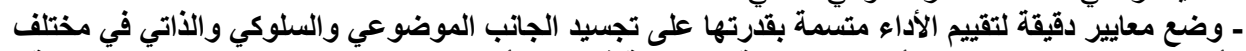

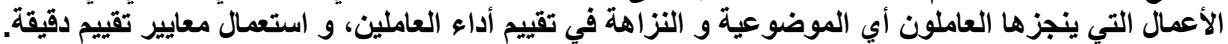

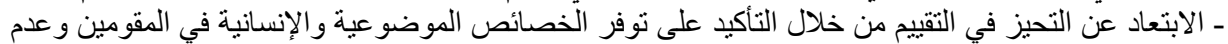

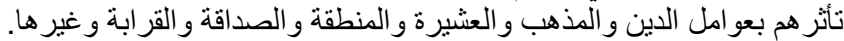

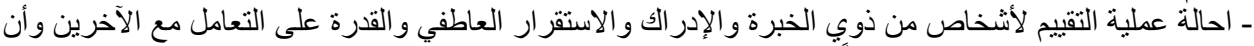
يكون التقييم من قبل فريق وليس فردياً.

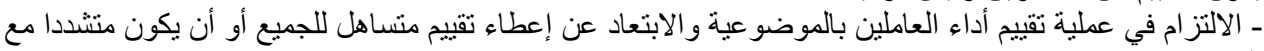

$$
\text { الجميع - الإن }
$$

- عدم التركيز على الأداء الأحدث و اهمال الأداء خلال السنة بأكملها . ـ استخدام إدارة الموارد البشرية لمختلف أساليب تقييم الأداء التقليدية منها و الحديثة مع الإطلاع الدائم على ما بيتجد في هذا المجال.

- يجب أن ترتبط عملية التقييم بالإجر اء الإداري و القانوني الموافق، ففي حالة الأداء الجيد يجب أن أن يحصل العامل

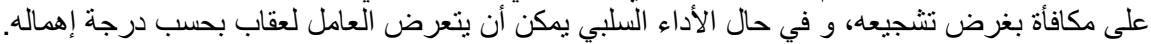

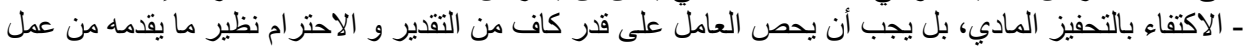
متقن في المنظمة. ـ لا يجب أن الكون الرنّة الرقابة على الأداء رقابة لصيقة مباشرة لأنها ستؤدي إلى مضايقة العمال، و سبصبح الأمر أكثر استفز از الهم.

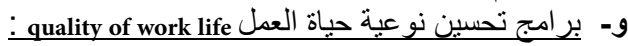

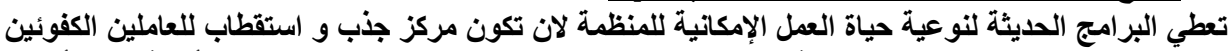

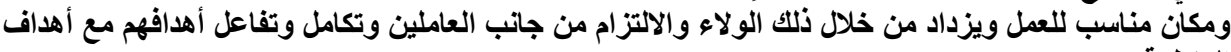

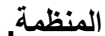

لقد استحدثت الكثير من البرامج الحديثة إضافة لبرامج التقليدية لتحسين نوعية حياة العمل مثل برامج التم صيانة

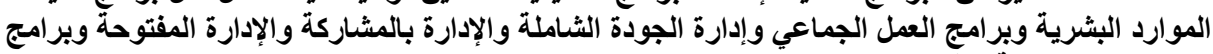

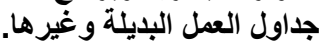

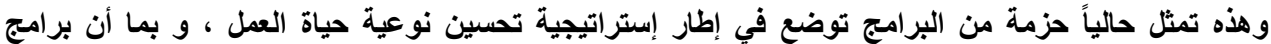

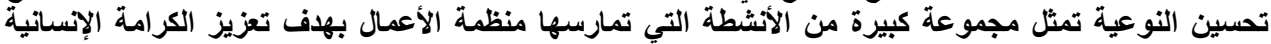
والنمو والتقدم والازدهار للعاملين ، لألك فإنها تمثل أهم المداخل الحديثة لتعزيز قدرة المنظمة للإيفاء بمتطلبات الإنة 
مسؤوليتها الاجتماعية والأخلاقية تجاه المجتمع ، ويمكن الإثارة لبعض جوانب ممارسة المسؤولية الاجتماعية من

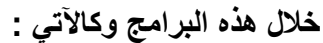

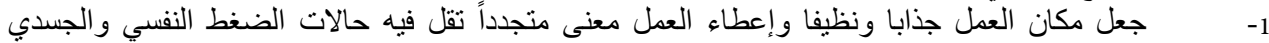

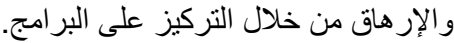
2ويشمل ذلك إثراء العمل و إغنائه.

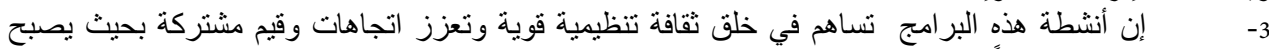
مكان العمل جذابا ومريحاً.

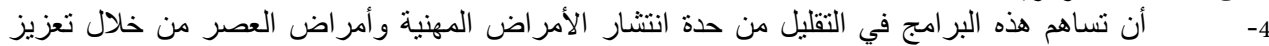

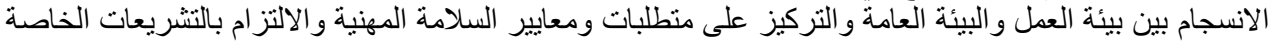
بها والنظر إلى مكان العمل من منطلق واسع.

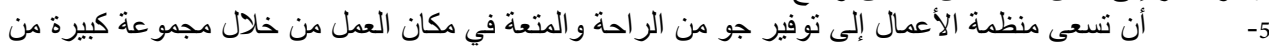

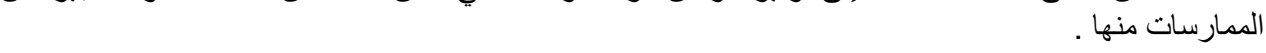

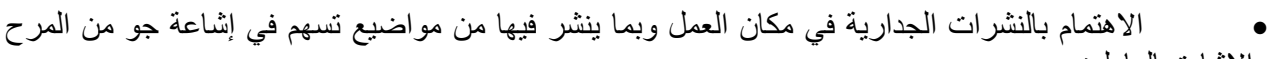
والإسادة بأعاملين. المناسيات الخاصة ، حيث تحتفل منظمة الأعمال بها وتقيم أنشطة ملائمة تتخلاهيا فعاليات بكافأ و الإشادة بالعاملين.

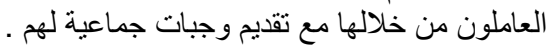

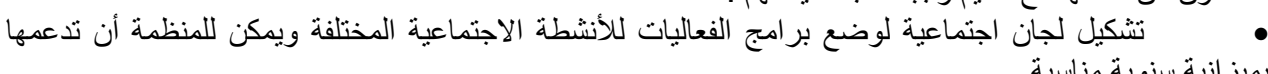
• بئرانة بطاقةات المناسبات حيث تشعر المنظمة العاملين فيها بالأهمية والمشاركة بالأفراح والثعور بالألفة والتواصل العمل بروح الجماعة. الاحتفالات بمناسبة أعياد ميلاد العاملين.

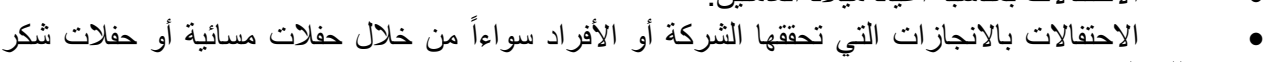
وتقدير للعاملين. تشجيع روح المرح و إثاعة جو عمل هادئ وودي.

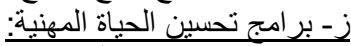

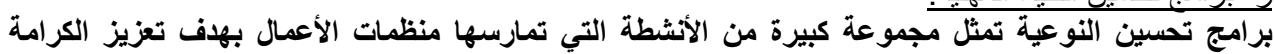

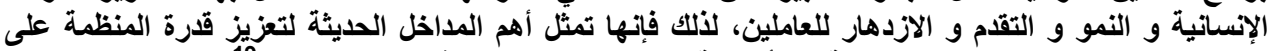

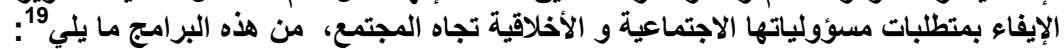

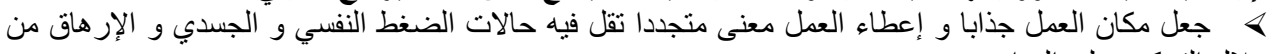

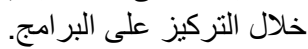

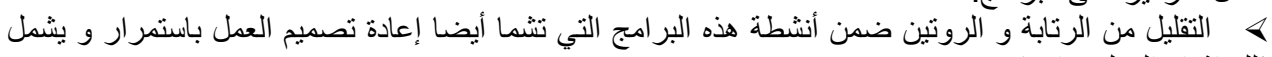
ذللك إثراء العمل و اغنائه. > إن أنشطة هذه البرامج تساعد في خلق ثقافة تنظيمية قيمة و تعزز اتجاهات قيم مشتركة بحيث يصبح مكان

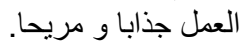

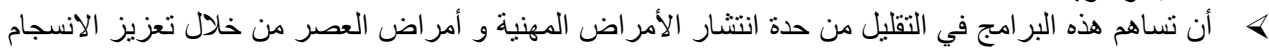

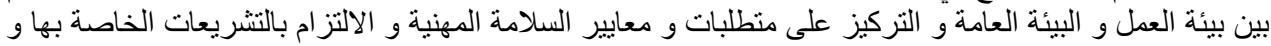

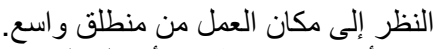
\& أن تسعى منظمة الأعمال إلى توفير جو من الراحة و المتعة في مكان العمل من خلال مجموعة كبيرة من الاهتمام بالنشر ات الجدارية في مكان العمل بما ينشر فيها من مواضيع تساهم في إنشاعة جو من المرح و

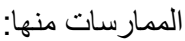

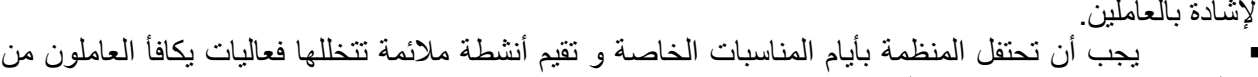
خلالها مع تقديم وجبات جماعية لهم.

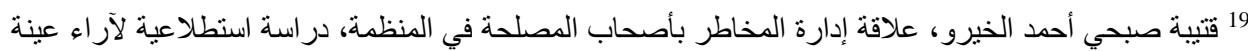

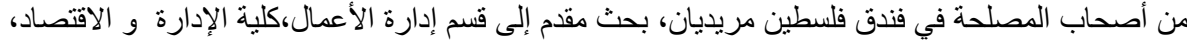

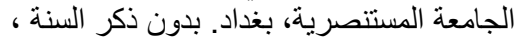


The impact of Business Ethics on the management of human resources ....

• تثكيل لجان اجتماعية لوضع بر امج الفعاليات للأنشطة الاجتماعية المختلفة و يمكن للمنظمة أن تدعمها بميز انية سنوية مناسبة. بطاقات المناسبات تشعر العاملين بالمنظمة بالأهمية و المشاركة بالأفر اح و الثعور بالألفة و التو اصل و العمل بروح الجماعة.

الاحتفالات بمناسبة أعياد ميلاد العاملين.

الاحتفالات بالانجاز ات التي تحققها الثركة أو الأفر اد سواء من خلادل حفلات مسائية أو حفلات شكر و

تقدير للعاملين.

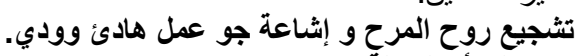
ص- المرأة العاملة: مئح

في أي مجتمع تحتل ألمر أة مكانة متميزة حيث أنها تمثل نصف هذا المجتمع، ويتميز العصر الحديث بدخول أعداد

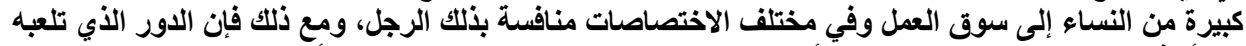

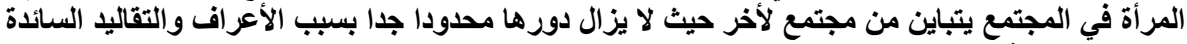

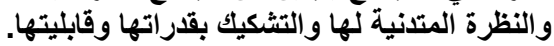

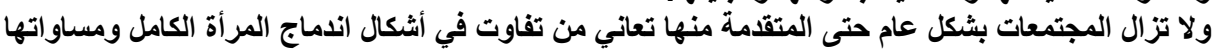

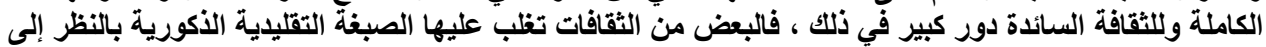

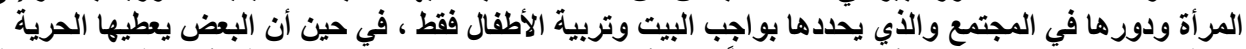

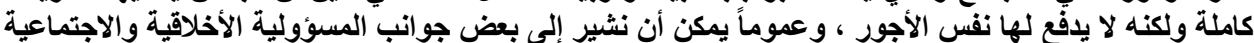

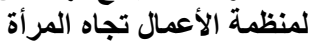
1. مكافحة المنظمة كافة أشكال استغلادل و ابتزازا لمرأة أمناة في مكان العمل ، فغالباً ما تتعرض النساء العاملات وفي

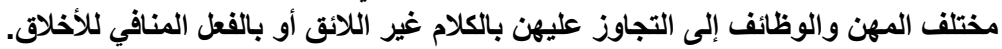

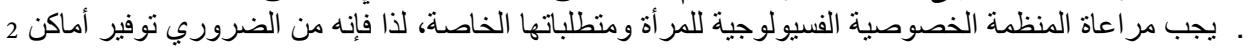
مناسبة تشنمل على احتياجات النساء العاملات.

3. تكفل القو انين بحدود معقول بلفئل بإجاز ات مدفوعة الاجر للمر أة أثناء الو لادة والأمومة ويفترض بمنظمة الأعمال

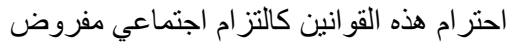

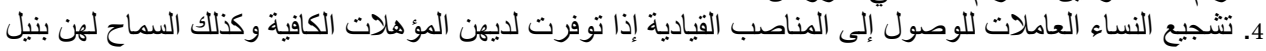

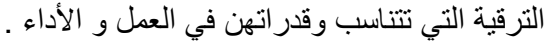
ي- المسار الوظيفي: هُ " مر اعاة سياسات المظيف: التوظيف المتعارف عليها قانونيا و احتر امها و عدم خرقها.

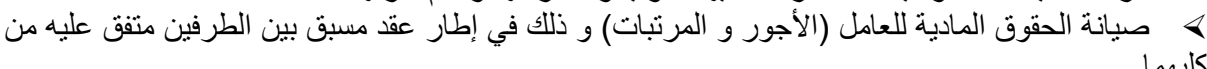
ه ك تحقيق المساو اة و العدالة بين العاملين من حيث الأجور و المكافآت و فرص التدريب و التكوين و الترفيع.

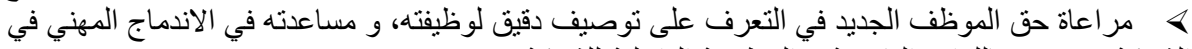

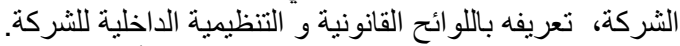

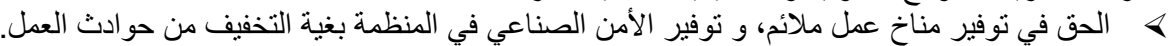

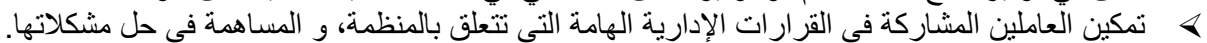

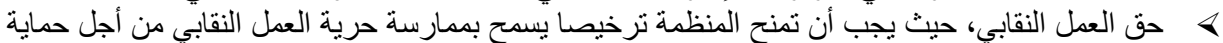
حقوق العاملين فيها. \& عدم استبعاد أي عامل من حقوقه في التدريب و التكوين من أجل تحسين أدائه و مهار اته.

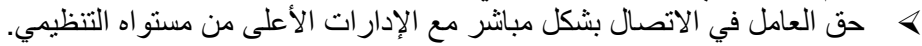

سنتطرق خلال هذا التطبقى للبحث:

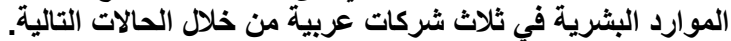

أولا: حالة: شركة الُّر المكو

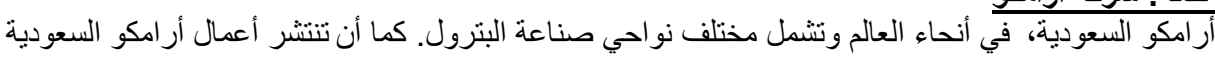

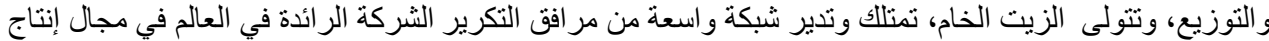

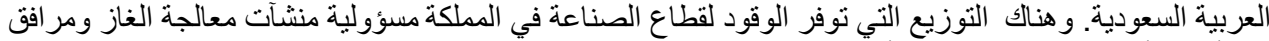

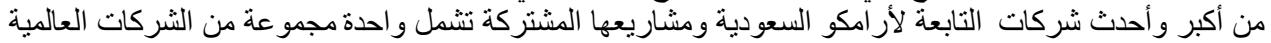

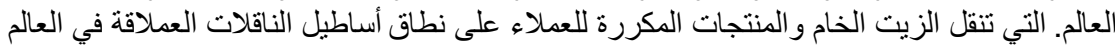




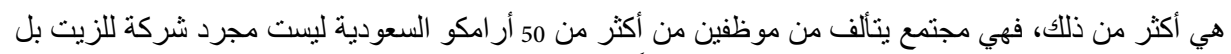

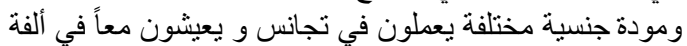

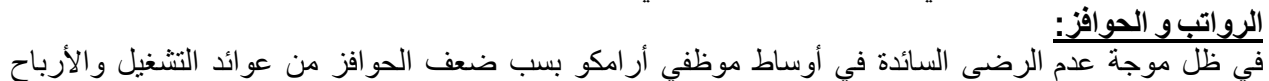
.1

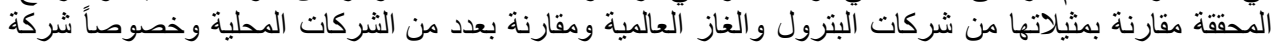

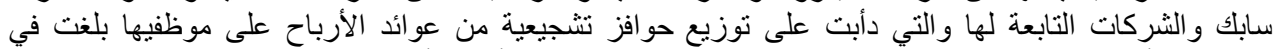

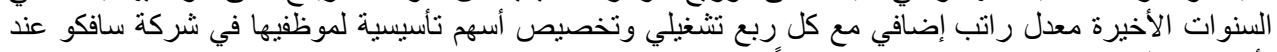

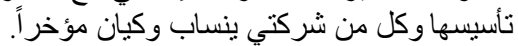

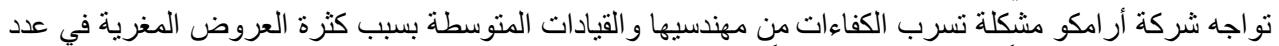

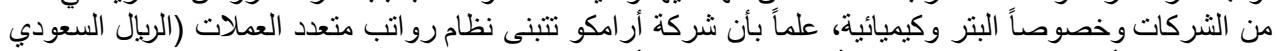

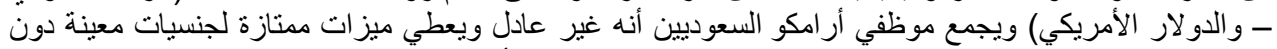

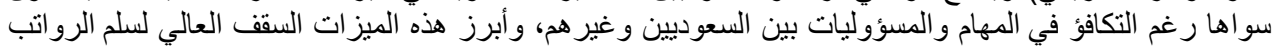
ومجانية التعليح.

ولمو اجهة هذه المشكلة تدرس أرامكو عدة خيار ات لتعديل سلم رواتب الريال السعودي ونظام الحو افز المعمول به.

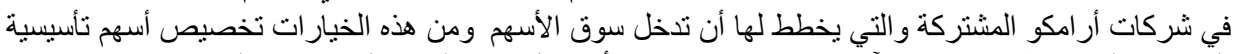

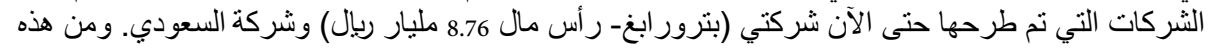

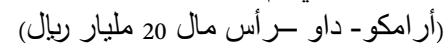

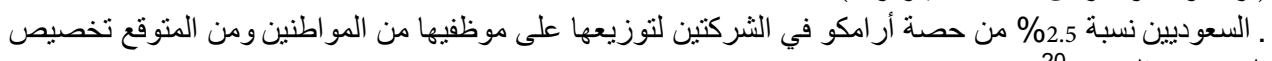
التكوين و التدريب:20:

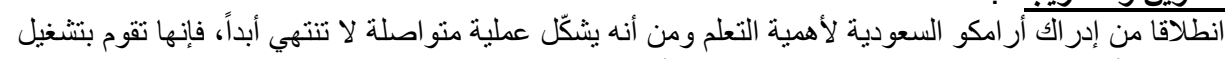

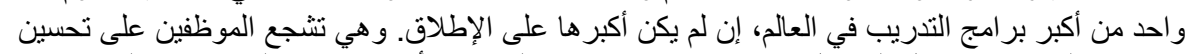

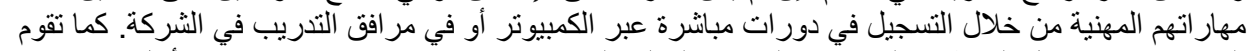

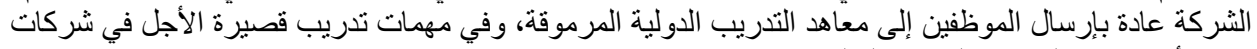

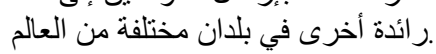
وتتراوح برامج التدريب المختلفة في الشركة بين البرامج المخصصة لغير الموظفين العديدة وبرامج التطوير المهني

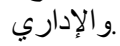
:نبذة تاريخية

بدأ اهتمام الثركة بالتعلم قبل نحو 60 عاماً بتأسيس مدارس مكونة من غرفة واركة واحدة فقط مبنية من هيكل خشبي

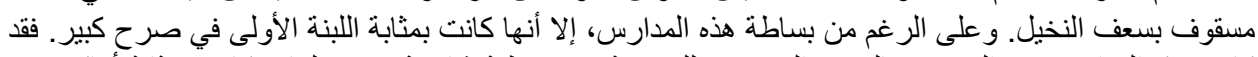

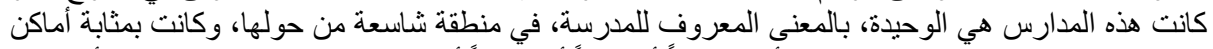

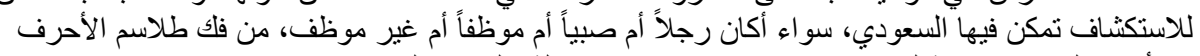

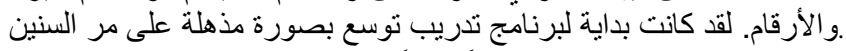

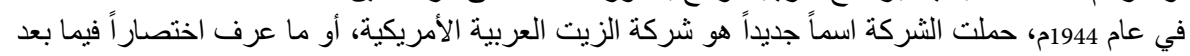

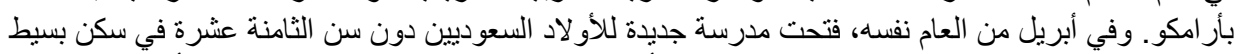

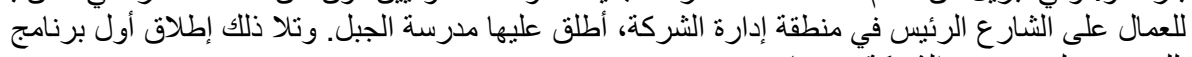

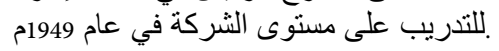

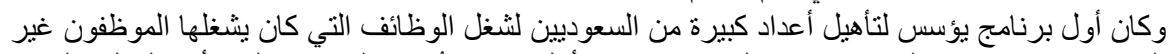

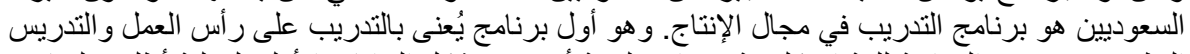

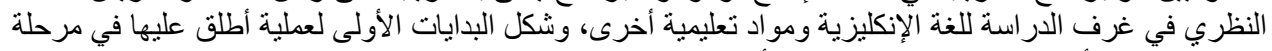

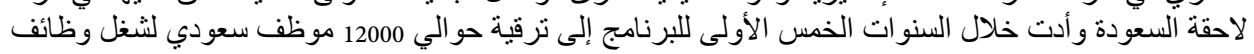

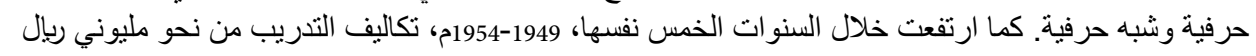

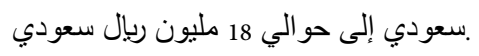

20 آل علي, رضا صاحب وسنان كاظم الموسوي. الإدارة لمحات معاصرة. عمّان: الوراق للنشر و التوزيع, 2001. 195 


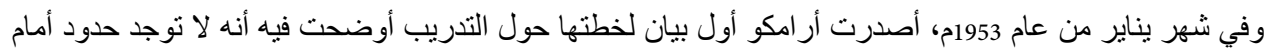

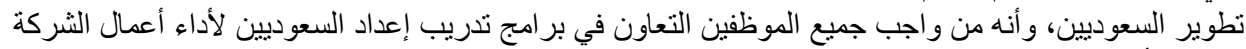

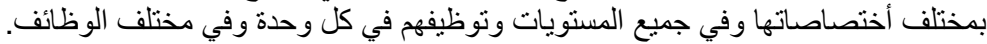

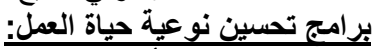

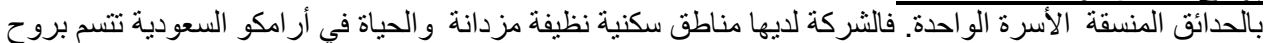

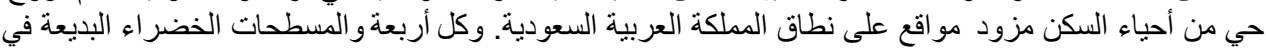

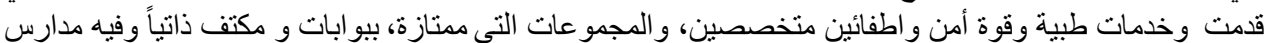

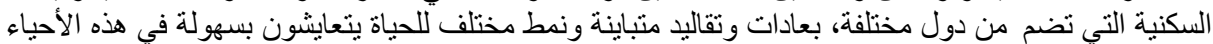

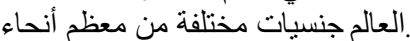

ثانيا: حالة: شركة سوناطر الك الجزائرية:

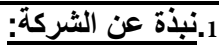

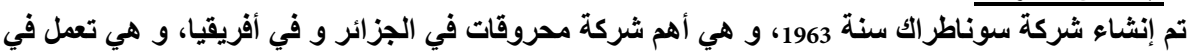

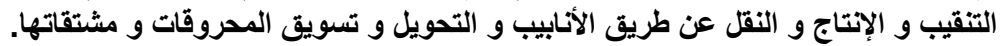

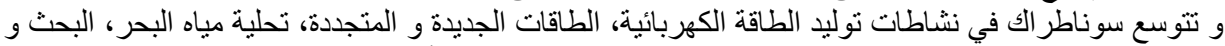

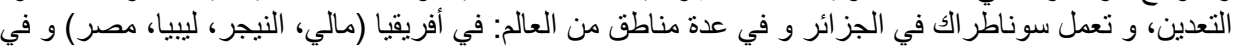

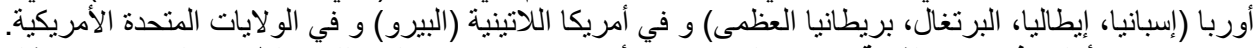

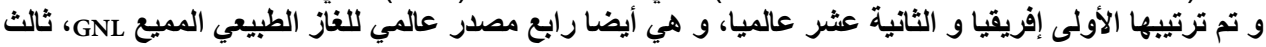

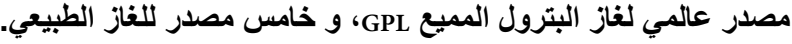

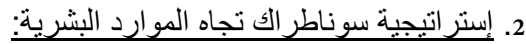
ن السياسة العامة: 1.2

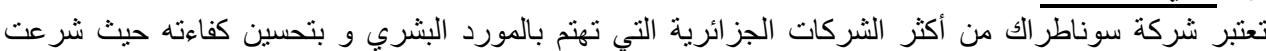

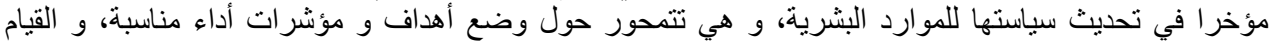

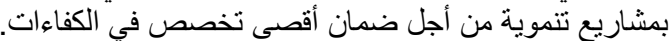

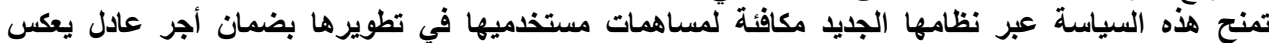

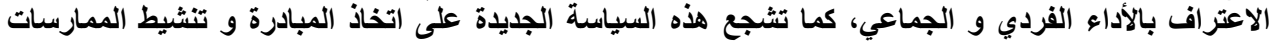
المهنية وربط نظام تسيير الأداء ربطا مباشرئرا مع نظام التعويضات. 2.2 تفضل سوناطر الك توظيف الكفاءات الثابة من ذوي الثهادات بالحرص الثرات على تطوير علاقات وثثيقة مع المدارس و الجامعات، بتسطير و إعلان فرص التطوير التي تمنحها لموظفيها المستقبليين. 3.2

تولي سوناطر الك أولوية كبرى لتتمية و تكوين و نطوير الموارد البشرية،حيث أن حو الي 55\% منهم معنيون بالتكوين

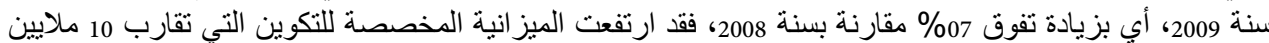
دو لار بنسبة 20\% مقارنة بالسنة الماضية.

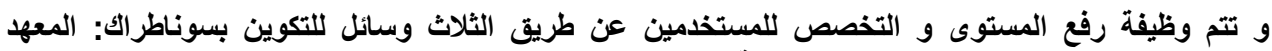

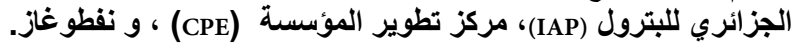

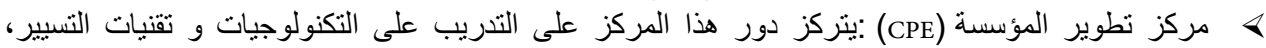
إدارة الأعمال، اللغات، تكوين المكونين، المالية و الثؤون القانونية، الإعلام الآلي و أنظمة الإعلام و الصحة ولتئ و

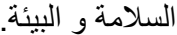

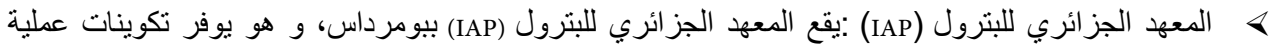

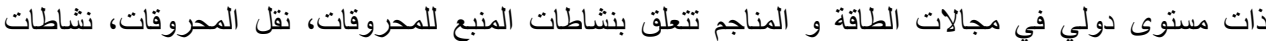

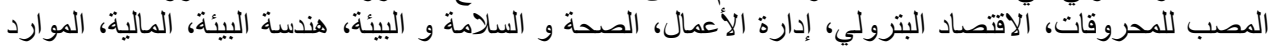

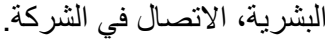

21 يوسف, درويش عبد الرحمن. العلاقة بين الإحساس بفعالية وموضو عبة نظام تقويم الأداء و الو لاء التنظيمي و الرضا والأداء الوظيفي: دراسة ميدانية. المجلة العربية للعلوم الإدارية. المجلد 6 العدد 2 مايو 1999. 
> معهد التكوين نفطوغاز (NAFTOGAZ) يقع مركز التطوير و تطبيق التقنيات البترولية و الغازية (نفطوغاز)

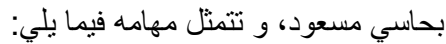

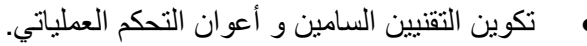

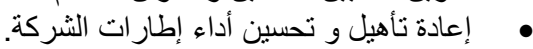

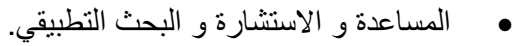
الاهتمام بالتوظيف النسوي: 4.2

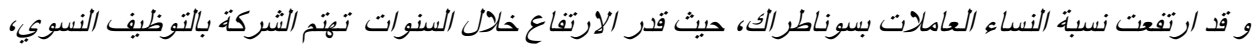

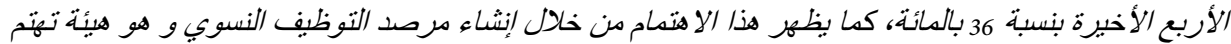

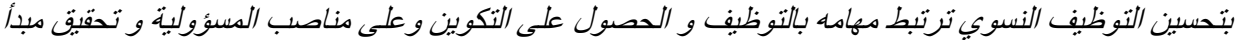
تكافؤ الفرص عند تساوي الكفاءات. 5.2

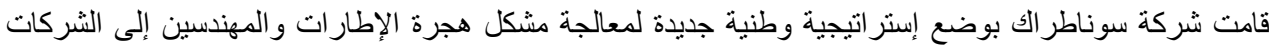

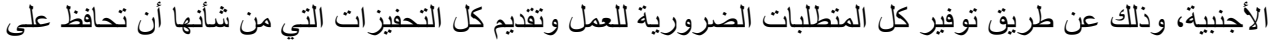
المو ارد البشرية للمؤسسة. 6.2 إصدار مدونة سلوكت لمجمع سوناطر الك:

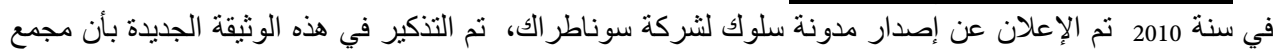

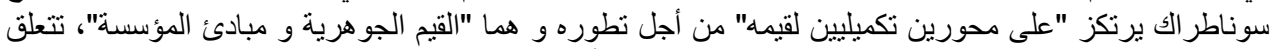

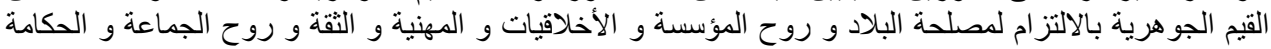

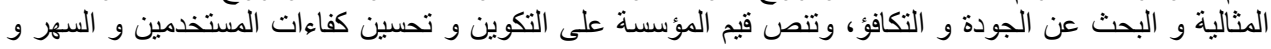

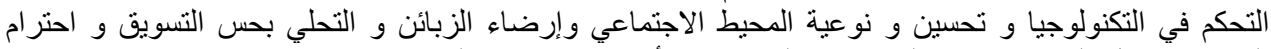

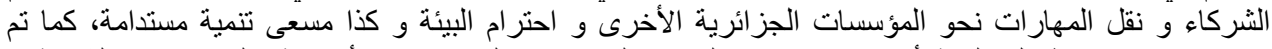

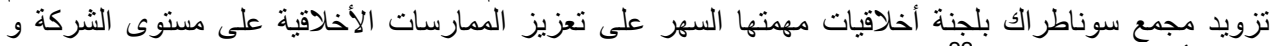

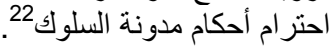

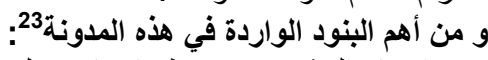

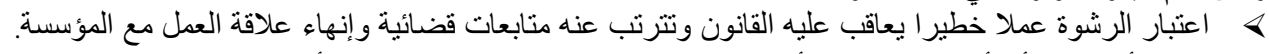

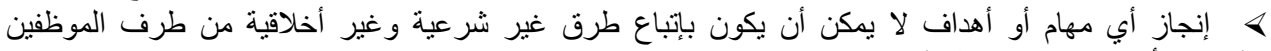

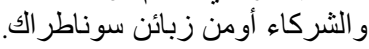

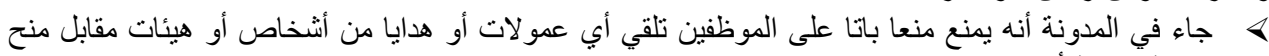

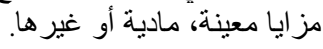

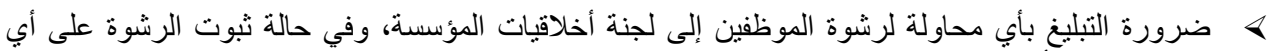

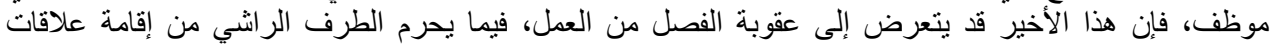

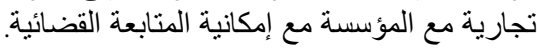

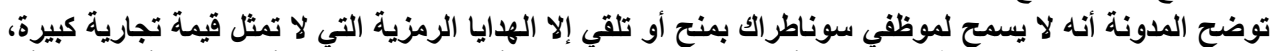

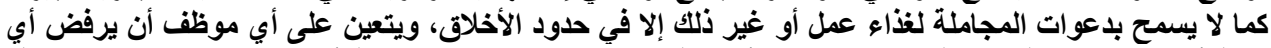

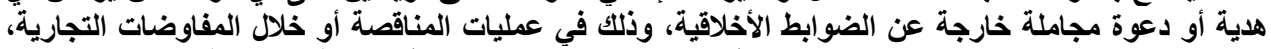

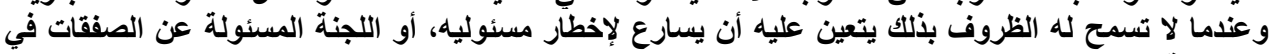

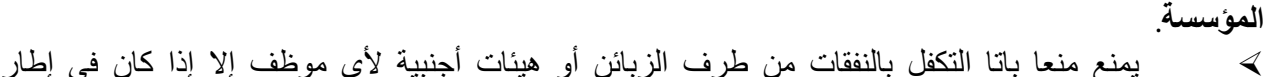
التزامات واضحة داخل العقود أو مرخصا من الجهات من طرئات المسئولة.

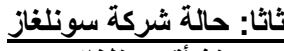
نشأة سونلفاز

22 موقع جز ايرس، مجمع سوناطر اكل ينشر مدونة سلوكه، (2011/10/20)، http://www.djazairess.com/aps/95987 23 موقع جز ايرس، سوناطر اك تصدر مدونة سلوك لمكافحة الرشوة بين موظفيها، (2011/11/1)، http://www.djazairess.com/annasr/7948 
الثركة الوطنية للكهرباء والغاز أو سونلغاز (بالفرنسية: Sonelgaz)، هي شركة عمومية جزائرية مجال نثاطها إنتاج

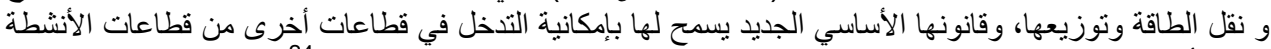

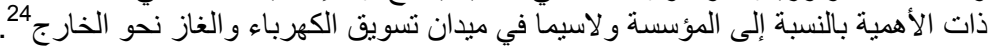

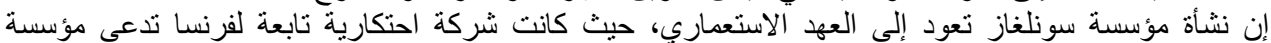

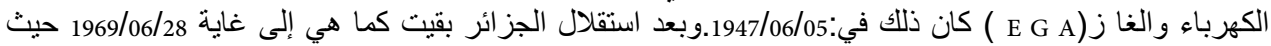

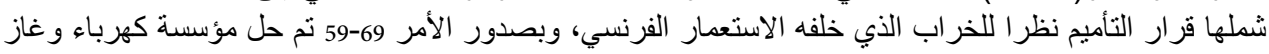

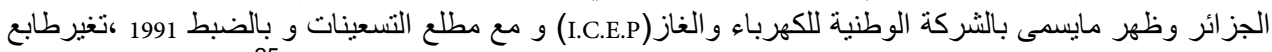

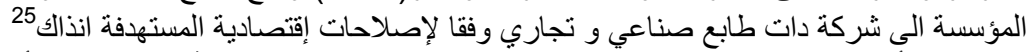

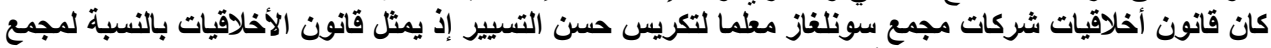

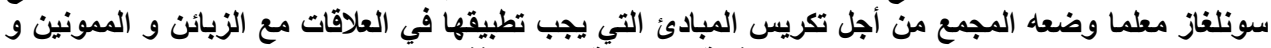

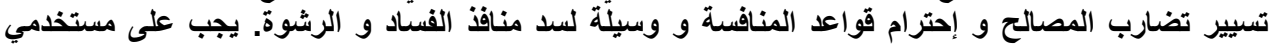
شركات مجمع سونلغاز الإلتزام باحتر إمبته

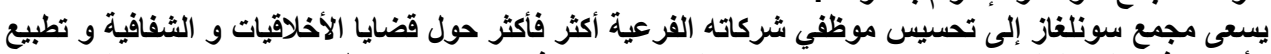

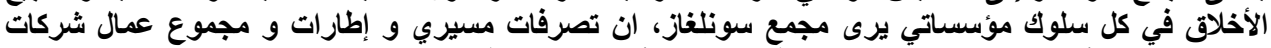

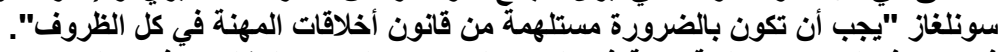

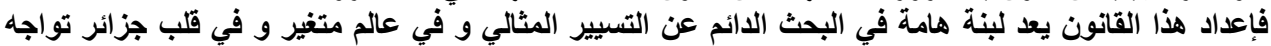

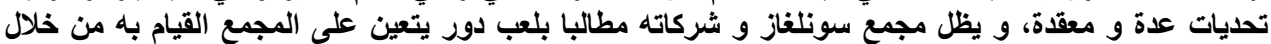

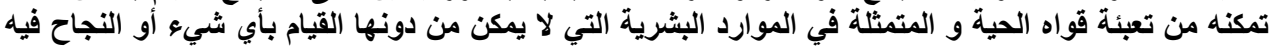

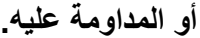

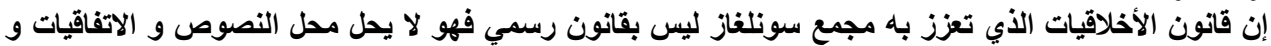

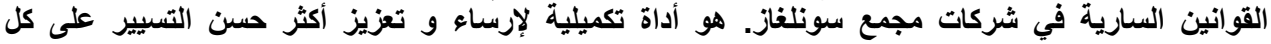

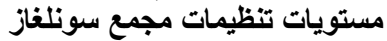
تعد سونلغاز من أولى الثركات التي تعززت بلجنات بلتة للتدقيق تخضع لسلطة مجلس الإدارة فقط، تتكون هذه اللجنة من إدارتين و أعضاء أحرار.

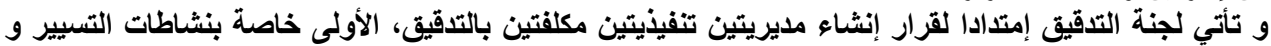

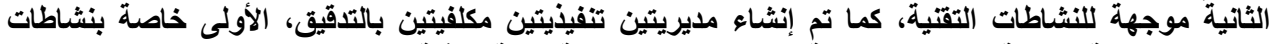

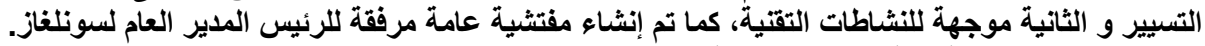

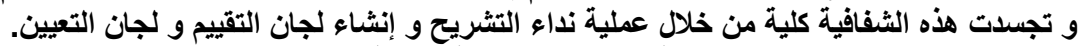

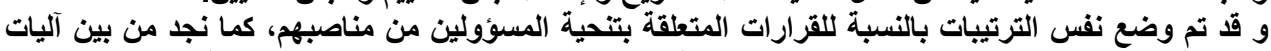

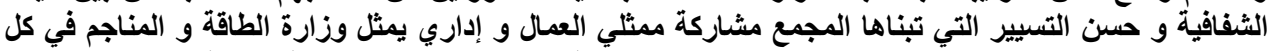

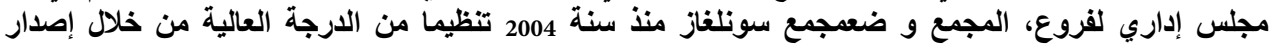
تعليمات بلغ عددها إلى يومنا هذا لفو 65 تعليمة.

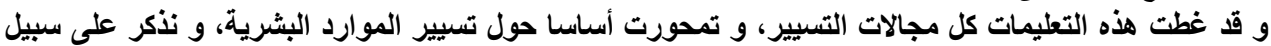

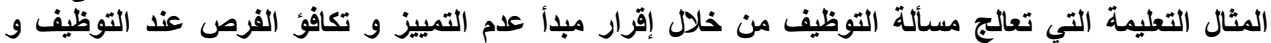

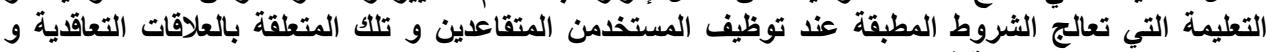

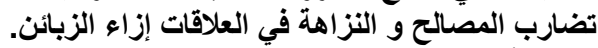

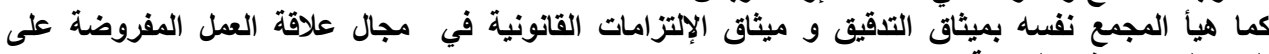

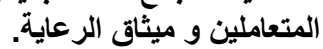
يجب أن يحظى هذا القئن القانون باحترام مطلق من قبل الجميع يتعين على كل عون لكل شركة أن يتمثل إليه و يلتزم

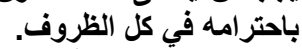
يتعين على كل شركة من شركات مجلَّمع سونلفاز إعداد قواعد داخلية مكيفة مع النشاطات الممارسة المتضمنة في

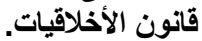

http://ar.wikipedia.org/wiki/\%D8\%B3\%D9\%88\%D9\%86\%D9\%84\%D8\%BA\%D8\%A7\% $\underline{\mathrm{D} 8 \% \mathrm{~B} 2}$ http://dc176.4shared.com/doc/e9TC_hT8/preview.html ${ }^{25}$ 


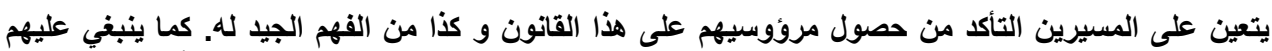

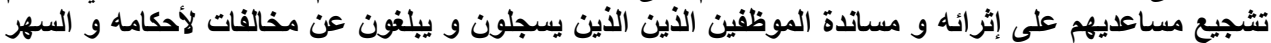

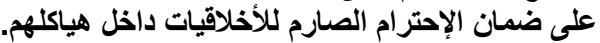

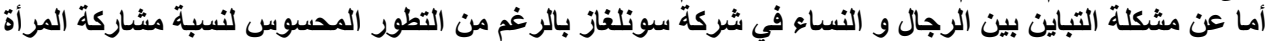

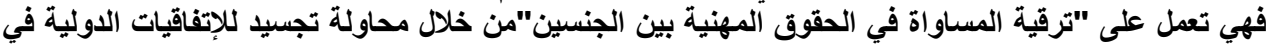

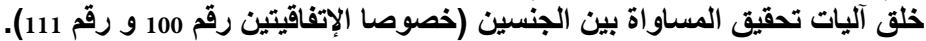

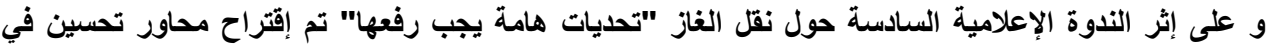
مجال الإجراءو و التنظيم و التكوين. و للنقابة دور جد فعال في حاضر و و مستقبل الثركة ـ محل الداراسة ـ ـ و في المجمع بأكمله، حيث أنها مطالبة

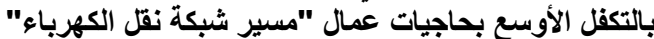

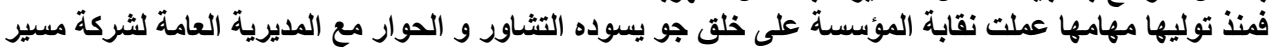

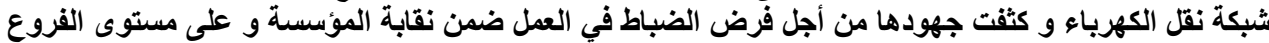

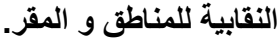

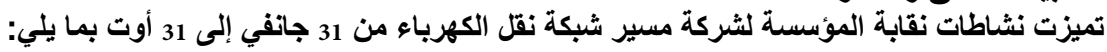
بالتوقيع على ملحقين إثثين للإتفاقية الجماعية:

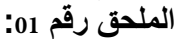
الإتفاق الجماعي رقم 2010/1 المتعلق ب: 1 2-

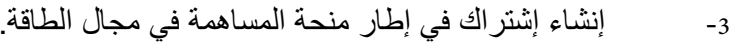

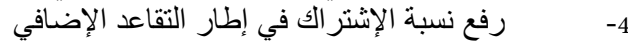

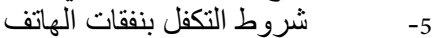
6-

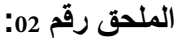
مكافأة اليوم العالمي للمرأة.

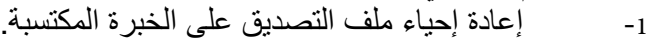

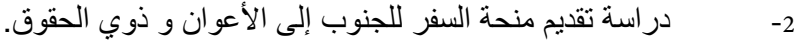

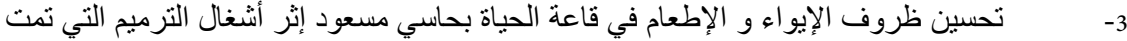

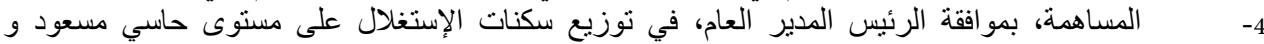

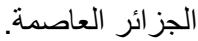

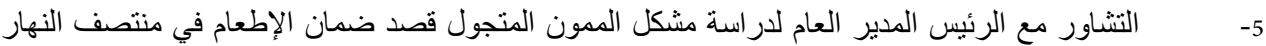
لمجموع مستخدمي مقر شركة تسيير نقل الكهرباء.

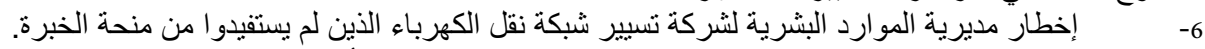

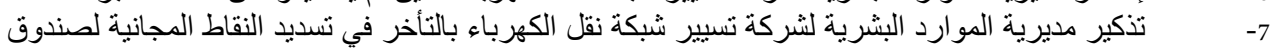

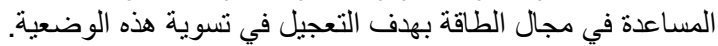

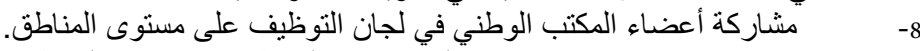

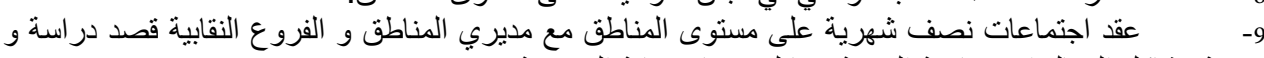

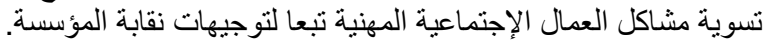

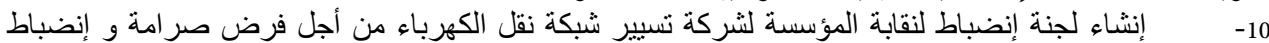

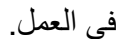
و و من آفاق نقابة شركة تسبير شبكة نقل الكهرباء.

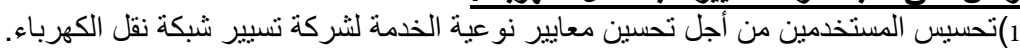

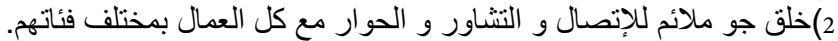

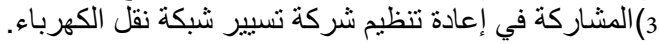
4) التكفل بالمشاكل الإجتماعية و المهنية للعمال. 5)متابعة سير المشوار المهني للعمال.

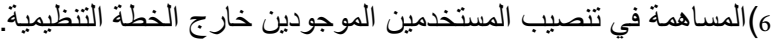

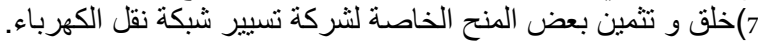
8) التعاون مع المديرية العامة قصد تسوية مشكل سكنات الاستغلال بالنسبة للأعوان المتقاعدين. 
9)در اسة توزيع سكنات متوفرة على المستخدمين الذين بضمنون الدئواومة.

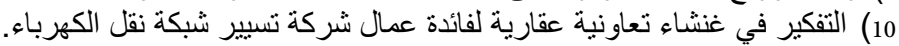

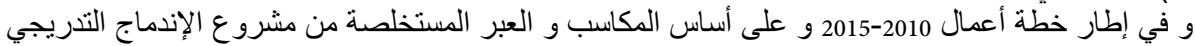

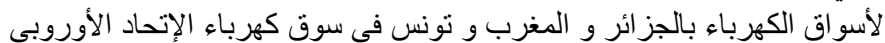

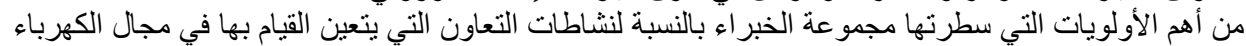
خلال الفترة 2010-2015 نجد: تعزيز كفاءات مختلف المتاعملين حول سوق البلدان الثريكة المتضمن:

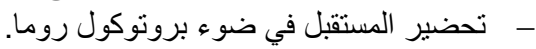
+

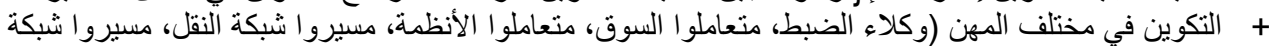

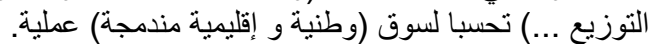
+

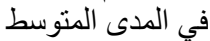
+ + +إنتتراك المستهلكين في حركية فتح الأسواق في المدى المتوسط

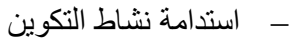

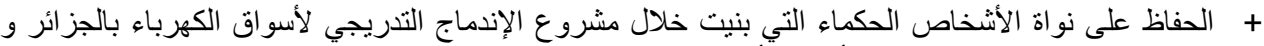

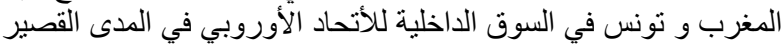

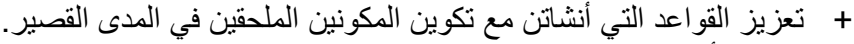

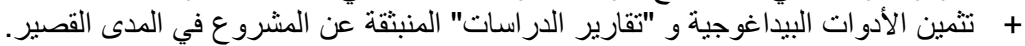

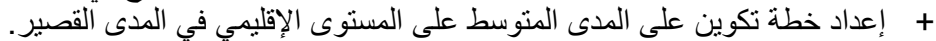

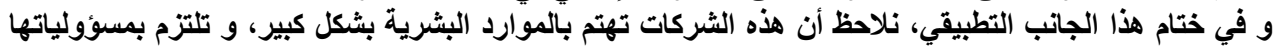

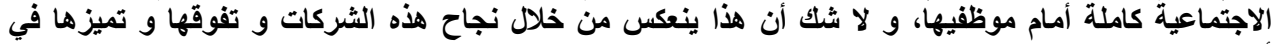

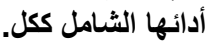

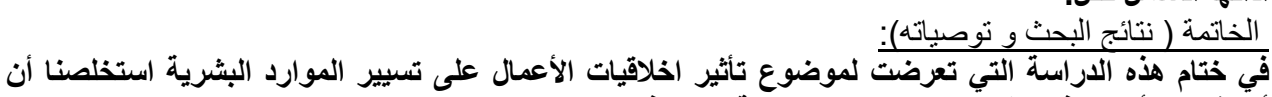

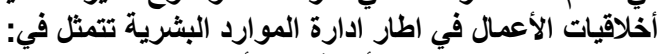

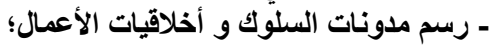

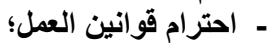

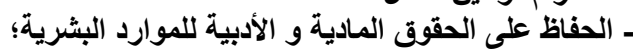

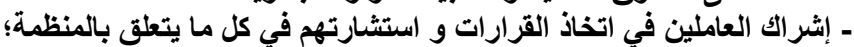

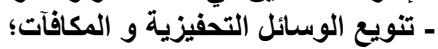

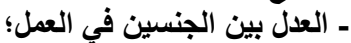

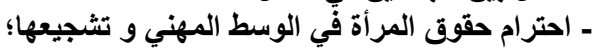

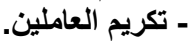

و في الأخير نعرض بعض النغ التوصيات المتعلقة بموضوع الاراسة:

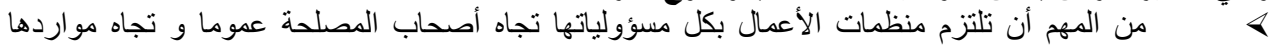

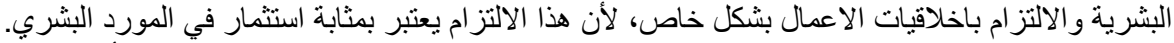

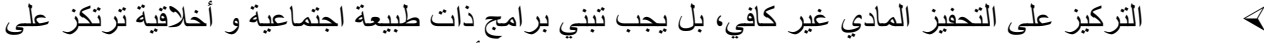

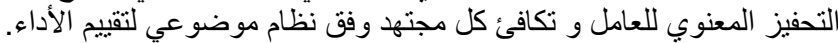

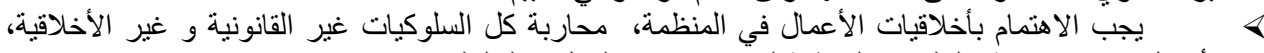

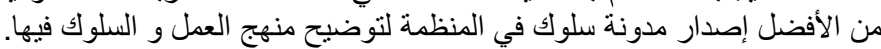

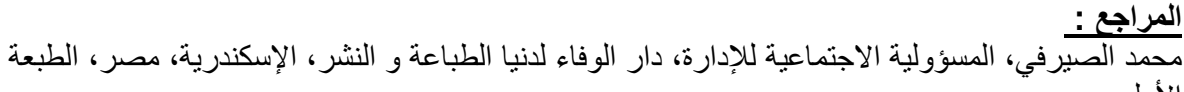

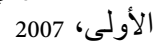

حسين الاسرج، المسؤولية الاجتماعية للشركات،مجلة جسر التتمية، سلسلة دورية تعنى بقضايا التتمية في الدول

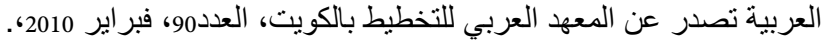

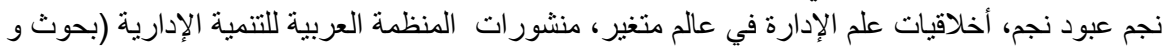

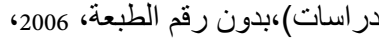




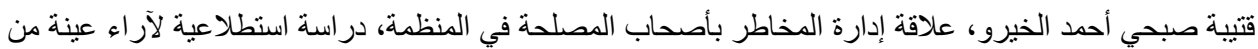

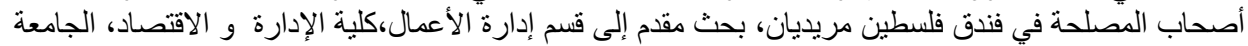

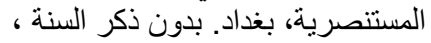

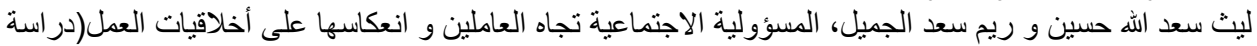

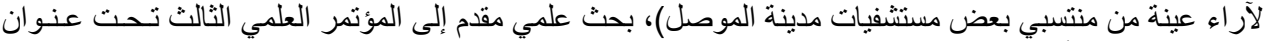

"إدارة منظمات الأعمال: التحديات العالمية المعاصرة"، كلية الاقتصاد و العلوم الإدارية جامعة العادية العلوم العادية التطبيقية

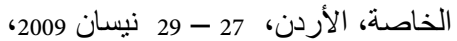

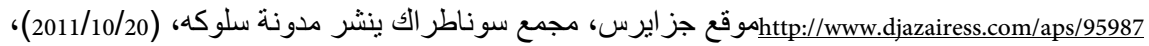
موقع جز ايرس، سوناطر اك تصدر مدونة سلوك لمكافحة الرشوة بين موظفيها، (2011/11/1)، http://www.djazairess.com/annasr/7948

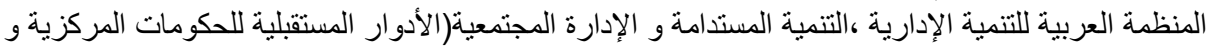

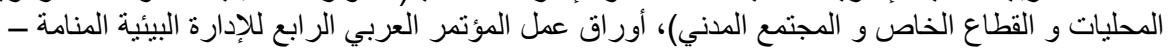

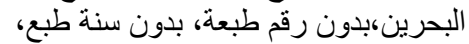

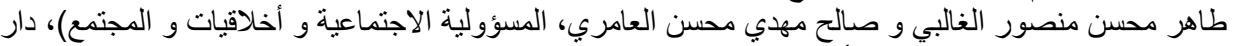

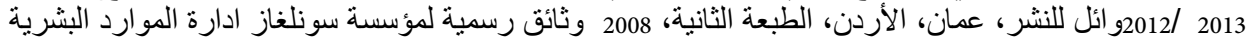

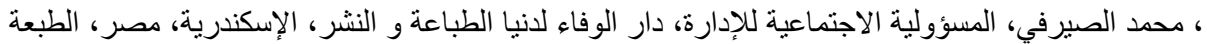

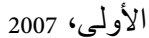

حسين الاسرج، المسؤولية الاجتماعية للثركات،مجلة جسر التنمية، سلسلة دورية تعنى بقضايا التنمية في الدول

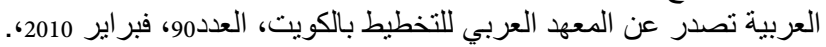
محمد الصيرفي، المسؤولية الاجتماعية للإدارة، دار الوفاء لدنيا الطباعة و النشر، الإسكندرية، مصر، الطبعة

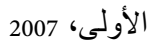

حسين الاسرج، المسؤولية الاجتماعية للشركات،مجلة جسر التتمية، سلسلة دورية تعنى بقضايا التنمية في الدول

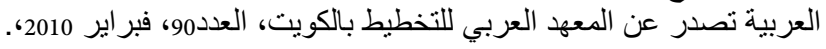

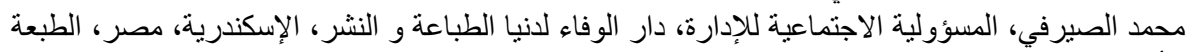

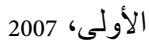

حسين الاسرج، المسؤولية الاجتماعية للشركات،مجلة جسر التنمية، سلسلة دورية تعنى بقضايا التنمية في الدول

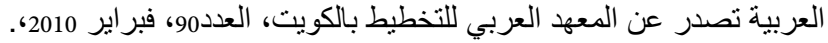
نجم عبود نجم، أخلاقيات علم الإدارة في عالم متغير ، منشور التبات المنظمة العربية للتنمية الإدارية (بحوث و

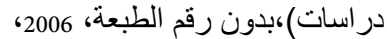

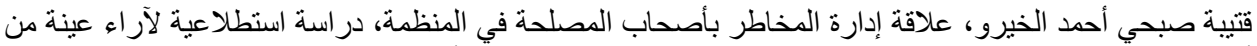

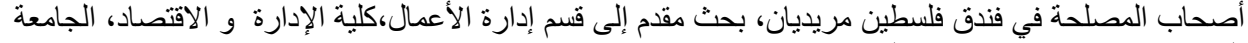

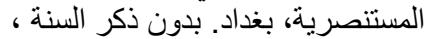
محمد الصيرفي، المسؤولية الاجتماعية للإدارة، دار الوفاء لدنيا الطباعة و النشر، الإسكندرية، مصر، الطبعة

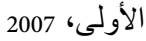

حسين الاسرج،المسؤولية الاجتماعية للشركاتهمجلة جسر التنمية، سلسلة دورية تعنى بقضايا التنمية في الدول

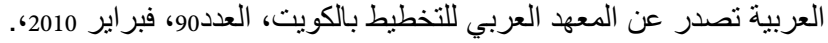

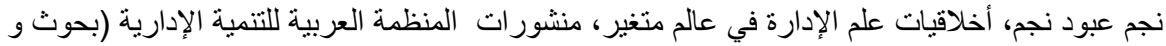

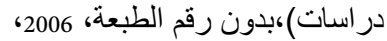

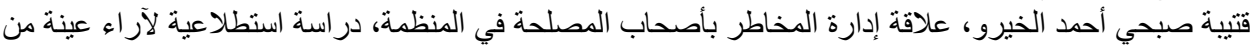

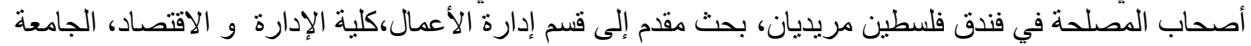

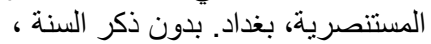
ليث سعد الله حسين و ريم سعد الجميل، المسؤولية الاجتماعية تجاه العاملين و العكاسها على أخلاقيات العمل(در استة

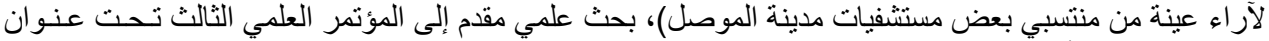

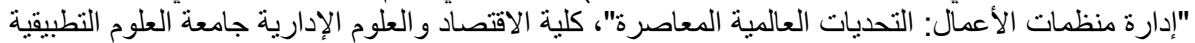

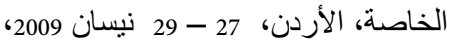

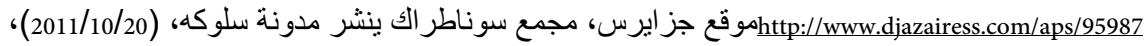
موقع جز ايرس، سوناطر الك تصدر مدونة سلوك لمكافحة الرشوة بين موظفيها، (2011/11/1)، http://www.djazairess.com/annasr/7948 


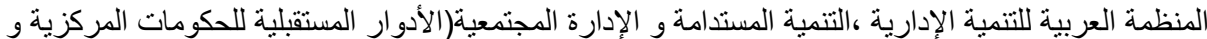

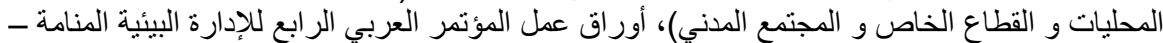

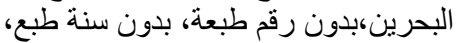

$$
\begin{aligned}
& \text { طاهر محسن منصور الغالبي و صالح مهاني محسن العامري، المسؤولية الاجتماعية و أخلاقيات و المجتمع)، دار } \\
& \text { 2013 /2012 الأردن، الطبعة الثنانية، } 2008 \text { وثثائق رسمية لمؤسسة سونلغاز ادارة المو ارد البشرية }
\end{aligned}
$$

\section{References:}

Mohamed Serafi, social responsibility management, fulfillment house to a minimum printing and publishing, Alexandria, Egypt, the first edition 0.2007 Hussein Alasrj, corporate social responsibility, Journal of Development Bridge, the journal concerned with development issues in the Arab countries issued by the Arab Planning Institute in Kuwait Series, No. 90, February 2010 ,. Star Abboud star, the ethics of management science in a changing world, the Arab Organization for Administrative Development publications (Research and Studies), without the edition number, 2006 Qutaiba Subhi Ahmed Aljer, risk management relationship with stakeholders in the organization, an exploratory study of the views of a sample of the stakeholders in the Palestine Meridien, research presented to the Department of Business Administration, College of Management and Economics, Al-Mustansiriya University, Baghdad. Without mentioning the

year, Laith Saad Allah Hussein and Reem Saad djamil, social responsibility towards workers and its reflection on the work ethic (the study of the views of a sample of employees of some of the hospitals in the city of Mosul), a scientific research presented to the third scientific conference titled "Business organizations management: global challenges contemporary", Faculty Economics and administrative Sciences Applied Science private University, Jordan, April 27 to 29, 2009, Dzaers site, Sonatrach publishes a blog his behavior, (20/10/2011), http://www.djazairess.com/aps/95987

Dzaers site, Sonatrach issued a code of conduct to combat corruption among its employees, (1/11/2011), http://www.djazairess.com/annasr/7948 Arab Organization for Administrative Development, sustainable development and community management (future roles of central and local governments and the private sector and civil society), Action of the Fourth Arab Conference on Environmental Management Manama, Bahrain papers, without No. edition, printed without the year, Taher Mohsin Mansoor Ghalibi and Salih Mahdi Mohsen al-Amiri, social responsibility and ethics and society), Dar Wael for Publishing, Amman, Jordan, the second edition 0.2008 official institution Sonelgaz documents HRM 2012/2013, Mohammed Sayrafi social responsibility management, fulfillment house the minimum Printing and publishing, $\begin{array}{llll}\text { Alexandria, } \quad \text { Egypt, the first } & 0.2007\end{array}$ Hussein Alasrj, corporate social responsibility, Journal of Development Bridge, the journal concerned with development issues in the Arab countries issued by the Arab Planning Institute in Kuwait Series, No. 90, February 2010 ,. Mohamed Serafi, social responsibility management, fulfillment house to a minimum printing and publishing, Alexandria, Egypt, the first edition 0.2007 Hussein Alasrj, corporate social responsibility, Journal of Development Bridge, the journal concerned with development issues in the Arab countries issued by the Arab Planning Institute in Kuwait Series, No. 90, February 2010 ,. Mohamed Serafi, social responsibility management, fulfillment house to a minimum printing and publishing, Alexandria, Egypt, the first edition 0.2007 Hussein Alasrj, corporate social responsibility, Journal of Development Bridge, the 
journal concerned with development issues in the Arab countries issued by the Arab Planning Institute in Kuwait Series, No. 90, February 2010 ,. Star Abboud star, the ethics of management science in a changing world, the Arab Organization for Administrative Development publications (Research and Studies), without the edition number, 2006 Qutaiba Subhi Ahmed Aljer, risk management relationship with stakeholders in the organization, an exploratory study of the views of a sample of the stakeholders in the Palestine Meridien, research presented to the Department of Business Administration, College of Management and Economics, Al-Mustansiriya University, Baghdad. Without mentioning the

year, Mohamed Serafi, social responsibility management, fulfillment house to a minimum printing and publishing, Alexandria, Egypt, the first edition 0.2007 Hussein Alasrj, corporate social responsibility, Journal of Development Bridge, the journal concerned with development issues in the Arab countries issued by the Arab Planning Institute in Kuwait Series, No. 90, February 2010 ,. Star Abboud star, the ethics of management science in a changing world, the Arab Organization for Administrative Development publications (Research and Studies), without the edition number, 2006 Qutaiba Subhi Ahmed Aljer, risk management relationship with stakeholders in the organization, an exploratory study of the views of a sample of the stakeholders in the Palestine Meridien, research presented to the Department of Business Administration, College of Management and Economics, Al-Mustansiriya University, Baghdad. Without mentioning the

year,

Laith Saad Allah Hussein and Reem Saad beautiful, social responsibility towards workers and its reflection on the work ethic (the study of the views of a sample of employees of some of the hospitals in the city of Mosul), a scientific research presented to the third scientific conference titled "Business organizations management: global challenges contemporary", Faculty Economics and administrative Sciences Applied Science private University, Jordan, April 27 to 29, 2009, Dzaers site, Sonatrach publishes a blog his behavior, (20/10/2011), http://www.djazairess.com/aps/95987

Dzaers site, Sonatrach issued a code of conduct to combat corruption among its employees, $\quad(1 / 11 / 2011), \quad$ http://www.djazairess.com/annasr/7948 Arab Organization for Administrative Development, sustainable development and community management (future roles of central and local governments and the private sector and civil society), Action of the Fourth Arab Conference on Environmental Management Manama, Bahrain papers, without No. edition, printed without the year, Taher Mohsin Mansoor Ghalibi and Salih Mahdi Mohsen al-Amiri, social responsibility and ethics and society), Dar Wael for Publishing, Amman, Jordan, the second edition 0.2008 official documents of the institution Sonelgaz Human Resource Management 2012/2013. 